IZA DP No. 8175

Do Informal Referrals Lead to Better Matches? Evidence from a Firm's Employee Referral System

Meta Brown

Elizabeth Setren

Giorgio Topa

May 2014 


\title{
Do Informal Referrals Lead to Better Matches? Evidence from a Firm's Employee Referral System
}

\author{
Meta Brown \\ Federal Reserve Bank of New York \\ Elizabeth Setren \\ MIT \\ Giorgio Topa \\ Federal Reserve Bank of New York \\ and IZA
}

Discussion Paper No. 8175

May 2014

IZA

P.O. Box 7240

53072 Bonn

Germany

Phone: +49-228-3894-0

Fax: +49-228-3894-180

E-mail: iza@iza.org

\begin{abstract}
Any opinions expressed here are those of the author(s) and not those of IZA. Research published in this series may include views on policy, but the institute itself takes no institutional policy positions. The IZA research network is committed to the IZA Guiding Principles of Research Integrity.

The Institute for the Study of Labor (IZA) in Bonn is a local and virtual international research center and a place of communication between science, politics and business. IZA is an independent nonprofit organization supported by Deutsche Post Foundation. The center is associated with the University of Bonn and offers a stimulating research environment through its international network, workshops and conferences, data service, project support, research visits and doctoral program. IZA engages in (i) original and internationally competitive research in all fields of labor economics, (ii) development of policy concepts, and (iii) dissemination of research results and concepts to the interested public.
\end{abstract}

IZA Discussion Papers often represent preliminary work and are circulated to encourage discussion. Citation of such a paper should account for its provisional character. A revised version may be available directly from the author. 


\section{ABSTRACT \\ Do Informal Referrals Lead to Better Matches? Evidence from a Firm's Employee Referral System*}

Using a new firm-level dataset that includes explicit information on referrals by current employees, we investigate the hiring process and the relationships among referrals, match quality, wage trajectories and turnover for a single U.S. corporation, and test various predictions of theoretical models of labor market referrals. We find that referred candidates are more likely to be hired; experience an initial wage advantage which dissipates over time; and have longer tenure in the firm. Further, the variances of the referred and non-referred wage distributions converge over time. The observed referral effects appear to be stronger at lower skill levels. The data also permit analysis of the role of referrer-referee pair characteristics.

JEL Classification: J30, J63, J64

Keywords: referrals, human resources, turnover, wage trajectory

Corresponding author:

Giorgio Topa

Federal Reserve Bank of New York

Research and Statistics Group

33 Liberty Street

New York, NY 10045

USA

E-mail: Giorgio.Topa@ny.frb.org

\footnotetext{
* This paper is dedicated to the memory of Linda Datcher Loury, a pioneer in this literature, an excellent scholar and a wonderful person. Stefania Albanesi, Laura Gee, Kevin Lang, Fabian Lange, Charles Bellemare, Manolis Galenianos, Bentley MacLeod, Uta Schoenberg, Wilbert van der Klaauw, Thijs van Rens, several reviewers, and seminar participants at Autonoma, Bocconi, Columbia, NY Fed, Pompeu Fabra, Sevilla, SED, SOLE, and UT Austin provided valuable comments. Susan Maloney contributed invaluable human resources expertise. The views and opinions offered in this paper do not necessarily reflect the position of the Federal Reserve Bank of New York or the Federal Reserve System.
} 


\section{Introduction}

There is an empirical consensus, both in economics and in sociology, on the widespread use of informal referrals in the labor market. ${ }^{1}$ For instance, Corcoran et al. (1980) analyze national data from the Panel Study of Income Dynamics (PSID) and find that between $52 \%$ and $58 \%$ of male workers under the age of 45 heard about their current job from friends or relatives; for their first job these estimates range between $55 \%$ and $67 \% .^{2}$ However, the information on referrals is often indirect, and there is little direct evidence on the impact of labor market referrals on the quality of the matches between firms and workers. ${ }^{3}$

We present new evidence on the empirical relationships among employment referrals and outcomes for workers based on a novel panel dataset on a single U.S. corporation, in which we observe both explicit referral status and a detailed picture of the hiring process and employment spell. We use these uniquely rich data to investigate the predictions of a long-established theoretical literature on labor market referrals, and to provide new descriptive evidence on the role of referrals at different skill levels and by provider-recipient relationship.

We find that referred candidates are more likely to be hired, and hired referred workers experience an initial wage advantage, all else equal, relative to non-referred workers. The initial referred wage advantage shrinks over time and dissipates by the third year of employment; starting with the fifth year the referral-wage relationship is reversed. Referred workers experience substantially less turnover, and their salary variance converges to that of non-referred workers over time. Each of these findings is consistent with the predictions of established labor market referral models, particularly those that view the distinction between referred and non-referred workers from the perspective of Jovanovic-style learning about match productivity. On the other hand, we find on average no differences in promotion rates between referred and non-referred workers: insofar as promotions reflect productivity, this finding is at odds with the theoretical literature, which tends to predict higher match productivity for referred workers.

\footnotetext{
${ }^{1}$ See Ioannides and Datcher Loury (2004) and Topa (2011) for surveys of the economics literature, and Marsden and Gorman (2001) for a survey of the sociology literature.

${ }^{2}$ See also Datcher (1983). Pellizzari (2010) analyzes a large panel dataset of European households (the European Community Household Panel) and finds that between $25 \%$ and $40 \%$ of respondents in most countries heard about their current job through informal contacts. On the employer side, Marsden (2001) and Holzer (1987b) using national surveys of U.S. firms report that a little over one third of firms surveyed in 1991 and in 1982 (respectively) use referrals from current employees in hiring.

${ }^{3}$ A notable exception is Datcher (1983), which we discuss below.
} 
Further, the wide range of skill and experience levels represented in this corporation permits detailed analysis of the role of referrals for workers at different staff levels. We find sizable, significant positive associations between referral and interview or offer probability for positions with lower education requirements. Most rank-and-file workers experience substantial referral salary advantages, with the largest estimated advantage going to support staff. The association between referral and tenure in the firm is large and positive for support staff, and it decreases more or less monotonically with staff level.

Our dataset also enables us to match referral providers and recipients within the firm, and therefore to construct measures of affinity between referrers and referred along various dimensions. Our analysis of the different types of referral matches yields some additional insights. First, we find that most referrals take place between a provider and a recipient with similar characteristics in terms of age, gender, ethnicity, education, as well as division and staff level within the corporation. This is consistent, on the one hand, with the well-documented extent of assortative matching in social networks, and on the other hand with the idea that referrals tend to be used by firms when they can provide a better signal about the referred worker's match productivity (assuming that higher affinity is associated with more informative signals).

Second, we find that referrals from employees that are older, in a higher staff level, or with relatively low tenure at the firm are associated with stronger salary advantages that tend to persist longer than average with tenure. These findings seem consistent with both a learning and a homophily story, where more senior or better informed employees may refer better quality new hires or reduce the noise around a new hire's match quality. In addition, referral providers from a different division than the recipient are associated with a steeper salary slope. The tenure and division findings in particular are difficult to reconcile with a "favoritism" or "influence" interpretation of referrals.

It is important to note here that this paper does not attempt to make any causal claims about the impact of job referrals on outcomes. We do not have, in our data, any exogenous source of variation in job candidates' or hired employees' referral status, nor do we observe a rich enough set of demographic or labor market characteristics to hope to control for selection into different job search methods. Our goal in this paper is to test the equilibrium predictions of leading models of labor market referrals, as well as to enrich our descriptive understanding of the behavior of referrals 
by provider-recipient relationship and across skill levels. Our results, by and large, support the predictions of learning-based models of labor market referrals.

The plan of the paper is as follows. Section 2 relates this paper to the rich and varied empirical literature on employee networks in general and referrals in particular. In Section 3 we review existing theory on labor market referrals and note several testable predictions. Section 4 describes our new firm-level data on job candidates and employee referral status, tenure outcomes, and promotion and salary trajectories. The empirical specifications used to test the various predictions generated by models of employee referrals, results of these tests and other empirical findings are found in Section 5. Section 6 concludes.

\section{Related empirical literature}

Empirical research on labor market referrals has emphasized the identification of effective proxies for referred worker status, as a result of the difficulty of measuring referral status in most relevant data sources. Recent research focuses on whether neighbors cluster in the same firm or area as an indication of the strength of informal referral networks (Bayer et al. 2008 and Hellerstein et al. 2011). Others study family based networks (Kramarz and Nordstrom Skans 2013) and educational institutions (Oyer and Schaefer 2012). Giuliano et al. (2009) and Aslund et al. (2010) find a relation between the ethnic status of managers and the ethnic composition of new hires using data from one large U.S. retail firm and Swedish social security data, respectively. Dustman, Glitz, and Schoenberg (2011) use ethnic minority groups as a source of variation in network distance between current employees and new hires in German employment data.

Three recent papers use direct data on referrals. Heath (2013) uses data on referrer-referred pairs from the Bangladeshi garment industry to test the predictions of a model in which referrals alleviate a moral hazard problem (the employer makes the referrer responsible for the referred worker's effort). Pallais and Sands (2013) study referrals with a set of field experiments in an online marketplace and find some evidence of selection and team production: referred workers perform better (even in jobs in which they have no contact with the referrer) and are more productive when working with their own referrer. Finally, Burks et al (2013) use data from nine large firms and find that referred workers are less likely to quit and exhibit higher performance on certain key 
productivity measures. They also find that referred workers look similar to non-referred ones both along observable characteristics and in terms of characteristics that are unobservable to the firm at the time of hire, such as cognitive and non-cognitive ability. ${ }^{4}$

With regard to the impact of referrals on hiring probabilities, Holzer (1987a) finds that the probability of obtaining a job or receiving an offer through personal contacts is higher than that through formal methods. Holzer (1988) also finds that among all search methods, informal methods (personal contacts and direct applications) generate the most offers and acceptances conditional on offer. The high fraction of jobs found through informal means reflects both high usage and high productivity of these methods. ${ }^{5}$ With regard to match outcomes, Datcher (1983) uses PSID data and finds lower turnover (quit rates) in jobs found through personal contacts rather than formal means, for black and college educated workers but not for those with high school educations or less.

Four revealing studies of referral based on firm-level data and explicit referral information address the subject from a sociological perspective. Fernandez and Weinberg (1997), Fernandez, Castilla, and Moore (2000), Fernandez and Castilla (2001) and Castilla (2005) use data from a retail bank and a call center to study the role of referral networks in hiring for low to moderate skill jobs. Much of the focus of these papers is on the hiring stage, and on initial productivity. Major findings include that referred applicants are more likely to be hired after controlling for other observables, that referrers do have relevant information about referred employees and that there is some evidence of assortative matching between referrer and referred. ${ }^{6}$ Castilla has direct measures of worker productivity from a call center and finds that referred workers are in fact more productive.

However, these studies do not follow employees for long post-hire periods, and they generally do not focus on testing labor market models. Our study is the first, to our knowledge, to use explicit data on individual employees' referral status to relate referrals to both immediate and long-term employment outcomes including starting salary, salary trajectory over time, promotion patterns

\footnotetext{
${ }^{4}$ Features of our data that differentiate this paper from the above include information on workers of widely varying skill and income levels within the same firm, and a long window in which to observe post-hire employment trajectories.

${ }^{5}$ In a seminal paper, Granovetter (1973) shows that information transmission about jobs is more likely to occur through weak rather than strong social ties. Gee and Jones (2012) revisit the "strength of weak ties" hypothesis using Facebook data and find that, while more matches are produced by weak ties as a result of their prevalence, an individual strong tie is more likely to produce a match than an individual weak tie.

${ }^{6}$ In addition, Fernandez and Galperin (2012) take a stab at studying the causal effect of referrals on the probability of being hired by using data on repeat applicants to a large retail bank. They find that referral applications are about five times as likely to result in interviews than non-referred ones.
} 
and stability of the job match, and hence we are the first, again to our knowledge, to be able to test the collection of predictions generated by the theoretical literature on employee referrals regarding salary trajectories, promotion and turnover using explicit data on employees' referral status. In addition, we observe various measures of affinity between referrer and referred along several dimensions, so we can study whether and how these referral effects vary depending on the nature of the match between referral provider and receiver.

\section{Theoretical models of employment referrals and their predic- tions}

The two leading descriptions of the role of referrals in the labor market, learning and homophily, are modeled in Simon and Warner (1992) and Montgomery (1991). Simon and Warner embed employee referrals in a Jovanovic $(1979,1984)$ learning model of job matching and turnover, and use this partial equilibrium framework to derive predictions for differences in salary and match duration between referred and non-referred workers. As a result of their partial equilibrium, dynamic framework, testing the types of predictions generated by the Simon and Warner model requires immediate and ongoing observation of referred and non-referred workers in a single employment spell, a task for which our panel of firm-level data is particularly well suited. ${ }^{7}$ Montgomery models employers who rely on referrals from high ability workers to alleviate a potential adverse selection problem in hiring (not being able to observe the "type" of a prospective employee). Homophily in worker networks implies that high ability employees will be more likely to refer other high ability workers.

More recent theoretical papers on employee referrals also favor one of these approaches or the other. Dustmann, Glitz and Schoenberg (2011) and Galenianos (2013) allow referrals to affect firms' information in models of employer and employee learning about worker productivity. Dustmann et al. model both initial worker-firm contact in referral and external markets and the ongoing wage negotiation over time between a matched worker and the firm. In this sense, their approach

\footnotetext{
${ }^{7}$ Note that Simon and Warner test the predictions of their old boy network model using the 1972 Survey of Natural and Social Scientists and Engineers, a collection of retrospective self-reports on employment experiences. We discuss their findings in conjunction with our own empirical results below. While our data have the advantages of being roughly 30-50 years more recent, being derived from an administrative source and representing a considerably wider range of worker skill levels, their data have the obvious advantage of representing more than one firm.
} 
suits our data particularly well. The Dustmann et al. model draws heavily on the specification in Simon and Warner, which in turn is based on the job matching model of Jovanovic. Hence the various approaches on which we pin our tests of the learning model share common assumptions and intuition.

Galenianos (2012), on the other hand, drives the referral effect through homophily, and generates results that address the relationship among network density, aggregate employment and job search outcomes. Other conceptualizations of the role of referrals include alleviating a moral hazard problem via monitoring (Heath 2011 and Kugler 2003) and favoritism towards social network members, e.g. relatives (this possibility is explored, in an experimental setting, by Beaman and Magruder 2012). We discuss the predictions of these alternative models alongside the learning and homophily models, wherever possible, in light of our empirical findings.

Next we discuss several predictions of referral models. Each prediction arises from some subset of the specifications we have discussed, including both the simple and more comprehensive learning models, as well as models of homophily, monitoring, and favoritism. These predictions are tested below using our firm-level data. We summarize all predictions, and our main empirical findings, in Table 1.8

\subsection{Predictions}

Prediction 1: Referred applicants are more likely to be hired

In the context of the simple learning model, and as demonstrated in Ljungqvist and Sargent (2000), the probability of an acceptable offer for a worker and firm who have met through source $j$, where $j \in\{$ referred, external $\}$, decreases in both the reservation wage and the variance of the noise in the initial productivity signal. A fundamental assumption of the learning models is that the noise in the productivity signal is less variable under referral. However, this leads, in each model, to a higher reservation wage for referred workers. On net, the sign of the difference in the probability of hire between referred and external market candidates is ambiguous in Simon and Warner and in Dustmann et al. Galenianos (2013), on the other hand, generates reasonably weak conditions

\footnotetext{
${ }^{8}$ Since the central objective of this study is empirical, and many of these claims were first made elsewhere, we provide only modest detail on the derivation of each prediction. Demonstrations of several of the claims in a simple theoretical context are available from the authors.
} 
under which referred matches will more likely lead to hires. In general, hiring probabilities are not a primary target of learning models of referral, and the models have mixed predictions regarding relative hiring probabilities.

Other approaches, however, yield a clear prediction that referred workers are more likely to be hired. Montgomery (1991) and Galenianos (2012) emphasize worker homophily, leading workers referred by high productivity employees to be more likely to be hired. Heath (2013) explains referrals through moral hazard, and also would seem to predict that referred workers are more likely to be hired. Finally, in a favoritism interpretation of referrals, referred candidates would be more likely to be hired because of the influence exerted by the referrer.

Hiring rate predictions, by model category, are summarized in the first row of Table 1 . Note that the entries in the "Data" column of this table appear following a vertical divider; they will be addressed later in the paper.

\section{Prediction 2: Referred workers receive higher initial wages}

Dustmann et al., Simon and Warner, Galenianos (2012, 2013), and Montgomery all predict higher starting wages for referred workers. The intuition driving this result is similar in the learning models of Dustmann et al., Simon and Warner, and Galenianos (2013). Here, part of the value to the worker of an initial wage is the possibility that the match productivity will exceed the expected productivity, leading to a higher ongoing wage. The worker is shielded from worse than expected productivity matches by the ability to separate from the firm. Hence, as in Lundquist and Sargent, the initial reservation wage marks the full information reservation wage down by an amount that accounts for the up-side potential. The external market candidate, owing to a noisier signal, sees greater up-side potential to the match than the referred candidate, and marks her reservation wage down by more. Therefore, conditional on acceptance, referred workers have higher starting wages than external market workers in the learning models. This prediction holds even if the underlying match productivity distribution is the same across referred and non-referred.

The source of the difference in referred and external market initial reservation wages in Galenianos (2012) and Montgomery relies on homophily in referral networks. Assuming a higher average productivity of employed than of unemployed workers, referred candidates, as homophilous friends of employed workers, will have higher average productivity and receive higher initial wages. 
The implications of the moral hazard and favoritism models for initial wages are unclear: in the favoritism story in particular, if influence is focused solely on having a friend or relative hired, the candidate may be of lower quality on average and the initial wage may be lower than for a non-referred worker - but other forms of favoritism may result in higher initial wages as well. Under moral hazard, referred workers may be less productive in other jobs where they lack network connections, and their weaker outside options may result in lower wages. Other forces, however, may override this mechanism: for instance, in the context of the Heath 2011 model, if the minimum wage is binding then we would observe no differences in initial wages between referred and nonreferred. Initial wage predictions are summarized in the second row of Table 1.

\section{Prediction 3: The referred worker wage advantage diminishes over time}

The learning models of Dustmann et al., Simon and Warner, and Galenianos (2013) all make this prediction. Consider the limiting cases. If referrals are perfectly informative, then referred workers' wages will be fixed over time. Assuming a less than perfectly informative signal in the external market, the wages of surviving external market candidates will rise as uncertainty regarding their productivity resolves. Hence referred and non-referred wages will begin to converge. A related intuition applies for the limiting case of perfectly uninformative external market signals.

Dynamic predictions including this one, prediction 5 involving relative turnover between referred and external market workers, and prediction 7 regarding relative wage variances over time are a primary means of distinguishing learning from other descriptions of the role of referrals. ${ }^{9}$ Selection models based on homophily (favoritism) can generate wage and tenure advantages (disadvantages) for referred workers relative to non-referred, but - crucially - such differentials do not close with tenure in these models. This assumes that referral relationships are homophilous in general productivity (put differently, ability).

We speculate that one homophily model may produce similar wage and turnover dynamics to the learning model dynamics described here. If referral networks are homophilous in firm-specific

\footnotetext{
${ }^{9}$ Note that Simon and Warner also consider the predicted effect of referrals where signals regarding referred and non-referred workers' match productivities are equally informative, but referred workers are on average more productive. According to Simon and Warner, this model generates an initial wage advantage for the referred but similar wage growth for referred and non-referred workers, and they interpret findings on the time path of the wage advantage of referred workers as a test of the relative importance of mean productivity differences and productivity signal informativeness in explaining the referral advantage.
} 
productivity but not general productivity, then referred and non-referred workers face a common outside option, and the selection among non-referred workers on firm-specific productivity as either productivity is revealed or outside options appear is more exacting, creating convergence in the two groups' wages. ${ }^{10}$

Finally, the moral hazard model described in Heath (2013) generates the opposite predictions: it implies that both the level and variance of wages for referred workers increase with tenure relative to those of non-referred workers. Wage dynamics predictions are summarized in the third row of Table 1.

Prediction 4: Turnover is lower for referred workers

The lower turnover prediction in Dustmann et al. is analogous to the higher starting salary prediction in Dustmann et al. Given that referred workers are better matched to their firms than non-referred workers, the probability mass below the common match productivity reservation value that applies to all workers after productivity is revealed is greater for external market than for referred workers, and so more workers initially hired through the external market separate from their matches following productivity revelation. A similar logic applies in Simon and Warner.

Non-learning models that generate higher referred than external market worker productivity may also predict lower referred worker turnover. For example, if homophily-based referrals lead to better matches, then such matches may also be slower to dissolve. Matches based on the mutual monitoring potential of a referrer and referee may similarly lead to greater productivity and less fragile attachment to the firm. The implications of the favoritism story for turnover are again unclear: if influence was exerted merely to get a lower quality candidate hired, then turnover may be higher for such hires - but this may depend on the form of influence and on the position of the referral provider. Turnover predictions are summarized in the fourth row of Table 1.

\section{Prediction 5: The referred turnover advantage also diminishes over time}

Though the simple two period model of Simon and Warner cannot address patterns in turnover as tenure in the firm varies more finely, Dustmann et al. model a gradual process of true productivity

\footnotetext{
${ }^{10}$ Note that this model requires either some amount of learning about productivity, even if the noise for the two groups is identical, or the ability to search on the job in order to generate meaningful dynamics.

Montgomery describes homophily in ability, which we interpret to be general and hence unlikely to produce convergence in wages and turnover. The predictions in Galenianos (2012) regarding network density and the business cycle, however, may well survive a restriction of homophily to similarity in firm-specific productivity.
} 
revelation. This approach allows members of the populations of referred and non-referred workers to be subjected to the common post-revelation reservation match standard gradually over time. As a result, surviving referred and non-referred employees gradually become more similar. Dustmann et al. provide numerical evidence that the difference in the rate of separation from the firm between referred and non-referred workers should diminish over time. Galenianos (2013) also predicts that referred and external workers become more similar over time.

Like the prediction for wage dynamics, this prediction regarding turnover dynamics offers an opportunity to distinguish among learning and other models of referrals. Models in which referred workers are more productive in a permanent sense may generate a referral turnover advantage, but this advantage generally does not decline over time. Hence prediction 5 applies to the class of learning models discussed here and not, for example, to Galenianos (2012), Montgomery, and Heath. Richer turnover dynamics are summarized in the fifth row of Table 1.

\section{Prediction 6: Referred workers have higher expected productivity}

The higher reservation match productivity of referred workers predicted by the model of Dustmann et al. would seem to predict higher expected match productivity for referred workers in general. Simon and Warner make similar predictions regarding reservation match productivity, and the link to expected match productivity over the full distributions of referred and non-referred workers is more direct in their simpler context. Further, Galenianos (2012) generates higher employer predictions of referred worker initial productivity in a homophily context. Greater initial or expected productivity of referred workers appears to be a relatively common prediction of the employee referral literature. In contrast, Heath (2013) predicts that referral recipients on average have lower quality than non-referred, because, thanks to monitoring, the firm can make positive profits with observably worse workers that it would not otherwise hire. However, in terms of observed productivity on the job, monitoring by the referrer may reverse some of the underlying productivity differentials by inducing high effort.

Predictions of the favoritism model are often ambiguous, as they rely in part on the preferences and level of involvement of the influential referral provider. This makes it a particularly difficult model to refute. However, the prediction of the favoritism model for relative productivity is, arguably, unambiguous. Favoritism, definitionally, involves balancing the preferences of some influ- 
ential party against the productivity of the potential hire when making a hiring decision. Hence one would expect on average lower productivity for referred than non-referred workers under favoritism. Productivity predictions are summarized in the sixth row of Table 1.

Prediction 7: The variances of referred and non-referred workers' wages converge over time

The theoretical literature on referrals offers few clear predictions for the levels and tenure trends of salary variance among referred and non-referred employees. Datcher (1983) posits a simple model of "job shopping", in which "information gathered through knowing someone at the place of employment before hiring lowers the uncertainty about the quality of the match between worker and job." She finds that the variance of the unobserved component of the returns of a job to an individual worker is lower for referred than non-referred workers. The moral hazard model of Heath (2013), as noted earlier, generates the prediction that the variance of wages for referred workers increases with tenure relative to non-referred workers. This is because, in order to induce the appropriate level of effort, the wages of referred workers are made to depend on observed output whereas wages of non-referred workers do not depend on output.

In the context of the learning models, two opposing forces influence the relative variance of referred and non-referred workers' initial wage distributions. The first is the noisiness of the signal. A noisier signal leads the firm to place more weight on the population distribution of productivities when determining the initial offer. Insofar as the population distribution is common across candidates, a noisier signal leads to less varied initial wages for external market workers. The second force arises from the difference in referred and external market acceptance thresholds. Under fairly weak assumptions, higher reservation wages will lower the variance of initial wages for referred workers relative to those of external market workers. Thus, the relationship between the variance of initial wages for referred and for non-referred workers is a priori ambiguous. On the other hand, a simple learning model with a common underlying productivity distribution would seem to predict convergence of variances with tenure, since both effects would tend to dissipate over time. However, more work is needed to generate more precise predictions for the second moment of wages in the context of referrals models. We summarize the predictions mentioned here in the seventh row of Table 1.

Prediction 8: The referral effect decreases with the skill level of the job market. 
While several empirical studies, discussed below, describe a larger role for referrals in job search among low skilled workers, few theoretical models of referrals generate predictions for the referralskill relationship. The primary exception is Galenianos (2013). In his learning model, Galenianos produces both more prevalent reliance on referrals and larger referral effects on wages and turnover for lower productivity firms. ${ }^{11}$ Presuming an association between firm productivity and worker skill in equilibrium, we interpret this as a prediction of greater reliance on referrals and larger referral effects on wages and tenure in low skill markets. These insights constitute the final prediction in Table 1.

\section{Data and descriptive statistics}

This study utilizes a unique dataset that includes all of the 2000-(April) 2011 hires and 20062010 applicants of a mid-sized U.S. corporation. The firm allows us to state that it employed a relatively stable number of workers over the period, and that this number lies somewhere between 2000 and 5000 workers. The corporation hires people for a broad range of tasks with all levels of educational backgrounds and years of work experience. The corporation operates in the financial services industry, is set in an urban labor market, and has been active for several decades.

\subsection{Applicant data}

The applicant data include how the applicant found the position, whether through the corporation's website, campus recruiting, internet job boards, employee referrals, their own initiative, or another source. ${ }^{12}$ The outcomes for the applicant are then traced through the interview, offer, and acceptance stages. Observed characteristics of the applicant are limited, but the data include detailed information on the position, including education and experience requirements, date of posting, and staff level. We divide the range of staff levels into support, junior, mid-level, senior, and executive positions. Referrals may be reported by the applicant, the referrer, or both. In any case, once the applicant gets to the interview stage, the information on the referral source is verified by the

\footnotetext{
${ }^{11}$ This is consistent with a puzzling empirical finding in the literature, namely that referrals are associated with higher wages in firm-level studies or when controlling for firm fixed effects; whereas the wage advantage is weaker or even reversed in analyses that do not control for firm characteristics. See Dustman et al. and Galenianos (2013) for a discussion.

${ }^{12}$ All but two of the roughly 62,000 applications in our sample indicate a single source.
} 
corporation's human resources (HR) department. For many positions, if the employee referral leads to a hire, the employee who provided the referral receives a small monetary bonus. ${ }^{13}$ The (nominal) bonus from 2000-(April) 2011 ranged between $\$ 500$ and $\$ 4,000$, with a mode of $\$ 1,000$ and a median around $\$ 2,000$.

The estimation sample is restricted to include only job postings that receive more than one applicant and result in a hire. ${ }^{14}$ We remove internships because they have very short durations (hence the hiring process is arguably different), and postings that were only internal. The meaning of a referred, or a non-referred, former employee is unclear both practically and in the context of the theory. Hence when current or former employees apply, we include them in the calculation of the applicant pool size, but drop their individual observations from the estimation. ${ }^{15}$

The final sample used in our analysis includes 62,127 applications for 315 positions, which resulted in 340 hires. Summary statistics appear in Table 2. On average, 185.2 individuals apply, and 6.7 interview, for a given posting. Though the table reflects substantial heterogeneity in posting characteristics, it is worth noting that most postings require at least a bachelor's degree, and just over half of the applications are for junior or support level staff positions.

\subsection{Employee data}

The employee data include a worker's referral status, staff level, shift, office location, full time, part time, or on leave status, salary, promotions, and turnover from the time of hire, which is left censored in April 2000, through departure, which is right censored in April 2011. ${ }^{16}$ Again, we include only first time hires and non-interns. ${ }^{17}$ Further, the employee data include only the main

\footnotetext{
${ }^{13}$ The newly hired worker must stay at the organization for longer than six months for the bonus to be paid. This condition does not seem to affect behavior: the separation rates for referred vs. non referred at 6 and 12 months of tenure are not statistically different. Family members, company executives, direct supervisors, and recruiters are not eligible for the award.

${ }^{14}$ Though a posted position may be associated with multiple vacancies, 91 percent of positions are associated with single vacancies.

${ }^{15}$ If a current or former employee is hired, we drop that position from the estimation. We also exclude postings through which workers were hired "in bulk".

${ }^{16}$ Workers are observed semiannually, in April and October. However, starting, promotion and termination or departure calendar dates are available. Since we observe salary only twice a year, the "starting salary" may be observed anywhere between the start date and six months later. Assuming a constant arrival rate of workers over the year, this would imply an average of 3 months' tenure when we measure starting salary. The firm's review process does not include a salary review for most employees before this date. Perhaps more importantly, the modal start month at this firm is September, so the tenure for a large number of employees when we measure starting salary is approximately one month.

${ }^{17}$ Interns are excluded from the sample because they are never promoted and they are attached to the corporation for a brief and externally determined period.
} 
location (because other minor locations were significantly scaled down over the sample period) and exclude the top executives of the corporation. Finally, we include only workers entering in 2000 or later, in order to follow each employment trajectory from the date of hire.

The resulting estimation sample includes 1,774 unique employees, $29 \%$ of whom were referred by current employees. All monetary variables in the paper are reported in 2010 U.S. dollars. Salary measures are reported in annual terms; annual salary includes base salary but not any performancebased pay. The salary figures and transition rates reported in the top panel of Table 3 are based on our 12,447 pooled employee semiannual observations. The mean and median annual salaries are similar, at $\$ 102,740$ and $\$ 97,377$, respectively. The standard deviation of salaries is substantial, at $\$ 45,551$, and the salary range, from about $\$ 20,000$ to over $\$ 300,000$, is quite broad. This salary range reflects the breadth of worker staff levels represented in the data.

Of the 1,774 unique workers ever observed in our sample, 1,005 (57 percent) are promoted during the sample window, and 638 (36 percent) leave the corporation. The mean observed tenure by 2011 or exit, whichever occurs first, is about three years. The mean time to first (any) promotion is $1.62(1.66)$ years.

One meaningful shortcoming of our data in the context of the broad literature on employment is the absence of data on hours of work. Our only measures of hours of work are indicators for part time and leave status. Roughly 97 percent of our pooled semiannual worker observations are full time, limiting the possible variation in hours. ${ }^{18}$ As a result of our lack of hours data, we are unable to infer hourly wages from annual salaries, and we take annual salary as our primary outcome variable in the earnings analysis. ${ }^{19}$

In addition, the data do not include either education at the date of first employment or work experience before applying to the organization. In order to estimate the log earnings regressions that are standard in the literature, we require schooling and experience variables. We address this data limitation using the staff category indicators described above. Since we observe the education and experience requirements for each job posting, we have a clear idea of the schooling and experience requirements associated with each staff level. We find that staff categories summarize schooling and experience requirements reasonably well. Hence we use staff level at entry indicators in our

\footnotetext{
${ }^{18}$ Of course, there could be substantial unobserved hours variation among those workers whom the corporation classifies as full time.

${ }^{19}$ Most employees at this corporation are paid on a biweekly basis.
} 
earnings estimation to proxy for the typical schooling, experience and experience squared regressors employed by the majority of the literature.

More generally, and as mentioned in the introduction, given the lack of rich enough data on demographic characteristics or labor market experience prior to joining the corporation, we cannot hope to address possible selection into different job search methods. Recent work by Pallais and Sands (2013) and by Burks et al. (2013) finds somewhat mixed evidence. Pallais and Sands find that selection may be important: in their experimental setting, referred workers performed better and separated less than non-referred workers even at jobs for which they were not referred and which their referrer was not present. In contrast, Burks et al. find that referred workers are indistinguishable from non-referred ones with regard to observable characteristics as well as characteristics that were not observed by the employer at the time of hire - such as various measures of ability. Thus, this remains an open question in this literature.

Finally, the reader should bear in mind possible measurement problems surrounding candidate referral. In order for a referral to go unreported, both the referrer and the candidate must fail to report it. The combination of the two events seems unlikely: the referral recipient has the incentive to mention the referral as it likely raises the chances of being offered the job; the referrer, on the other hand, has the incentive to "claim" the referral either for the monetary bonus or for other nonpecuniary benefits. If there is any under-reporting, as long as it is uncorrelated with the referred worker's characteristics, then it will likely only lead to an attenuation bias in our estimates. ${ }^{20}$ Second, and perhaps more importantly, it is possible that a current employee's decision to refer someone formally may be related to the candidate's success during the various stages of recruiting and interviewing. This possibility is limited by the details of the referral process: the latest that a current employee can "claim" someone as a referral is at the interview stage, when the recruiter reviews the candidate's initial application. Therefore, the referrer cannot decide ex-post to refer someone, after observing whether the person is actually hired or not. ${ }^{21}$

\footnotetext{
${ }^{20}$ However, if the employee's decision to report a referral is correlated with something unobservable about the candidate that in turn affects her employment trajectory, then it will be difficult to sign the direction of the bias.

${ }^{21}$ It is still possible, in general, that referral recipients may be "selected", as employees may choose to refer high quality candidates for a position in order to maintain or enhance their reputation within the company. This would be consistent with homophily models a la Montgomery (1991). It is also consistent with a learning model in which the means of the underlying productivity distributions differ between referred and non-referred. As we mentioned in Section 3, a key difference between homophily (in general productivity) and learning models is whether any referral advantages persist or dissipate with tenure. Our data enable us to distinguish between these alternative interpretations.
} 


\section{Empirical specification and findings}

\subsection{Model predictions}

Prediction 1: Referred candidates are more likely to be hired

A central prediction of Galenianos (2012, 2013), Heath (2013), and Montgomery (1991), as discussed above, is that referred workers are more likely to be hired, all else equal. This is also likely the case in a favoritism story. Our first empirical step is to test this prediction using our data on the corporation's applicant pool and resulting hires. Note that Castilla (2005), Fernandez and Weinberg (1997), Fernandez, Castilla and Moore (2000) and Fernandez and Castilla (2001) all confirm this prediction in their bank and call center single-firm hiring studies. Our test of this prediction extends their analysis to a broad range of skill levels and more recent hiring data, and, in addition, informs our findings regarding longer-term worker experiences for this particular corporation.

An initial perspective on this prediction is provided by the raw interview and job offer rates reported in Table 4. Job board applicants constitute 60 percent of the applicant sample. They also constitute 40 percent of interviewees and 24 percent of offer recipients and final hires. By contrast, referred employees constitute only 6 percent of the applicant sample, but 21 percent of interviewees, 27 percent of offer recipients, and 29 percent of hires. In other words, the pool of candidates receiving serious consideration increasingly favors the referred over the course of the hiring process. ${ }^{22}$

Adopting a more formal approach, we model the probability of being hired by the corporation in a linear probability framework. ${ }^{23}$ Specifically, we estimate

$$
H_{i j}=X_{i}^{H} \alpha^{H}+Z_{j}^{H} \beta^{H}+\gamma_{t}^{H}+\varepsilon_{i j}^{H},
$$

where $X_{i}^{H}$ is a vector of characteristics of applicant $i$ including indicators for applicant source among the set $\{$ referral, internet job board, corporate website, own initiative, other source $\}, Z_{j}^{H}$ is a vector

\footnotetext{
${ }^{22}$ No other applicant source shows as steep a consideration trajectory. Campus recruitment and other methods, relatively minor applicant sources for this firm, each produce more successful applicants than the job boards. However, neither achieves the conditional interview and hiring probabilities of the referral category.

${ }^{23}$ Our qualitative results are generally robust to a logistic specification. Results from a logistic specification analogous to (1) are available from the authors.
} 
of characteristics of job posting $j$ including number of applicants for the position, proportion of the applicant pool that is referred, the staff level of the position, the experience requirement of the position and the educational requirement of the position, $\gamma_{t}^{H}$ is a calendar year fixed effect, and $\varepsilon_{i j}^{H}$ is an idiosyncratic error associated with the applicant $i$ - posting $j$ pair.

The estimates generated using expression (1) are reported in Table 5. We estimate three versions of the model. In the first, we define outcome $H_{i j}$ as an indicator for whether applicant $i$ was interviewed for position $j$, and we estimate using the full sample of applicants. ${ }^{24}$ In the second, we define outcome $H_{i j}$ as an indicator for whether the applicant was offered position $j$, and we again estimate using the full sample of applicants. In the third, we condition the estimation sample on applicant $i$ having been interviewed for position $j .{ }^{25}$ We again define $H_{i j}$ as an indicator for whether the applicant received an offer. In this manner we are able to examine not only whether referrals are associated with a greater job offer probability, but also at what stage of the hiring process any estimated referral advantage is manifested. Outcomes for two applicants to the same posting are clearly correlated (though many postings result in multiple hires, and many others in no hires). Therefore we cluster errors $\varepsilon_{i j}^{H}$ at the level of the job posting, $j$.

Our central finding is that referred applicants are indeed more likely to be hired. Relative to job board applicants, referred applicants are estimated to be 7.3 percentage points more likely to be interviewed for the position, and 2.4 percentage points more likely to receive an offer. Conditional on having been interviewed, referred applicants are 13.9 percentage points more likely than job board applicants to receive offers. ${ }^{26}$ Each of these coefficient estimates for the referred category is significant at the one percent level. Further, based on a range of hypothesis tests of model coefficients, referred candidates are significantly more likely than those applying through the firm website or on their own initiative to be successful in all three of the modeled stages of the hiring process (columns 1-3 of Table 5). They are more likely to be interviewed than applicants from "other" sources. They are, however, insignificantly more likely to receive an offer than other source applicants. This need not be taken as evidence against the otherwise apparent hiring benefit of

\footnotetext{
${ }^{24}$ We impose the sample requirement that we observe all variables included in the Table 5 estimation for the applicant-position pair.

${ }^{25}$ This leaves us with a sample of 1,811 interviewees. Of these 1,811 interviewees, 428 are offered the position for which they interviewed.

${ }^{26}$ Note that 6.0 percent of job board applicants receive interviews and 32.3 percent of interviewees from internet job boards receive offers. Thus, relative to job board applicants, referral recipients are more than twice as likely to be interviewed and - conditional on interview - about $40 \%$ more likely to receive an offer.
} 
referral, in that the residual "other" category is largely comprised of campus visit-based hires, which, like referrals, draw on colleague networks.

\section{Prediction 2: Referred workers receive higher starting salaries}

Next we test the prediction that referred workers receive higher starting salaries. We consider a standard log earnings regression:

$$
\ln S_{i t}=\alpha_{0}^{L} r_{i}+\alpha_{1}^{L} \tau_{i t}+\alpha_{2}^{L} r_{i} \tau_{i t}+\alpha_{3}^{L} \tau_{i t}^{2}+\alpha_{4}^{L} r_{i} \tau_{i t}^{2}+X_{i t}^{L} \beta^{L}+\gamma_{t}^{L}+\varepsilon_{i t}^{L}
$$

where $S_{i t}$ represents the salary of worker $i$ at calendar time $t ; r_{i}$ is an indicator for whether worker $i$ was referred by a current employee of the corporation; $\tau_{i t}$ indicates tenure in the corporation for employee $i$ at time $t$; $X_{i t}^{L}$ is a vector of controls including a staff level indicator (as a proxy for schooling and experience) and indicators for company division, shift, work schedule, and leave status; $\gamma_{t}^{L}$ is a calendar year fixed effect; and $\varepsilon_{i t}^{L}$ is an idiosyncratic error. This log earnings regression is estimated using pooled data on employee half years, and allows us both to compare starting salaries for the referred and non-referred and to follow the effect of referral on employees' salary trajectories over time.

The estimated coefficient on referral in the log salary regression, reported in Table 6 , indicates a 2.1 percent starting salary premium for referred workers. ${ }^{27}$ The coefficient is significant at the one percent level. ${ }^{28}$ To the extent that this effect is precisely measured and of economically significant magnitude, it bears out the predictions of both learning models, like Dustmann et al., Simon and Warner, and Galenianos (2013), and homophily models, such as Montgomery and Galenianos $(2012) \cdot{ }^{29}$

\section{Prediction 3: The referred worker salary advantage diminishes over time}

\footnotetext{
${ }^{27} \mathrm{We}$ also estimated a set of starting salary regressions in levels (available upon request): the estimated referral effect is about $\$ 1,250$ with a $p$-value of 0.06 for the one-sided test. The magnitudes of the referral coefficient estimates in the linear and log salary regressions are roughly consistent, given mean and median salaries of $\$ 102,740$ and $\$ 97,377$, respectively.

${ }^{28} \mathrm{It}$ is worth noting that the fit of the salary models appears surprisingly high; $R^{2}$ 's are roughly 0.86 throughout Table 6, for example. The staff level categories included in the estimates are close proxies for particular educationexperience pairs, but also contain some information on the role of the worker in the organization. They are therefore very powerful predictors.

${ }^{29}$ Simon and Warner also show evidence of higher initial wages when recollected jobs were based on referrals in their retrospective 1972 survey of scientists and engineers.
} 
As discussed in Section 3.1, however, learning-based theories of labor market referrals predict that the referral effect will dissipate over time, and the salaries of referred and non-referred workers who remain with the corporation will converge. The log salary estimates reported in Table 6 provide a test of the referred salary premium's time trajectory. ${ }^{30}$

We find that the referral effect does indeed diminish over time. In the linear tenure specification in Table 6 column (1), $\alpha_{2}$, the coefficient on the interaction between the referral indicator and tenure in the organization, is negative and significant at the one percent level. In the quadratic specification, reported in column (3), the estimated values of $\alpha_{2}$ and $\alpha_{4}$ (i.e., the coefficients on the referral indicator multiplied by tenure and tenure squared) are both negative, though the coefficients are not estimated very precisely.

Figure 1 depicts predicted salaries for referred and non-referred workers as tenure increases. ${ }^{31}$ While the referred salary initially lies above the non-referred salary, referred and non-referred salaries are roughly equivalent after three years of tenure with the corporation. Indeed, 95 percent confidence intervals only rule out common referred and non-referred salary levels for the first two years of tenure in the corporation. This convergence of salaries after an initial advantage for the referred is consistent with the theoretical predictions of the Dustmann et al., Simon and Warner, and Galenianos (2013) learning-based models of labor market referrals, and seems at odds with the homophily, favoritism and moral hazard models discussed above.

From five years of tenure on, the estimates predict a statistically significant salary advantage for the non-referred. It is not clear what to make of this eventual non-referred advantage in the context of the theory discussed earlier. Models like Dustmann et al. and Simon and Warner predict some convergence in referred and non-referred salaries, but do not include a source of advantage for non-referred workers who stay with the corporation. As we show below, we also find that referred employees experience significantly lower turnover than non-referred. Taken together, these findings suggest a role for differential investments in firm-specific human capital, or perhaps for nonpecuniary gains related to differential affinity between employees already at the firm and referred

\footnotetext{
${ }^{30}$ Estimates of a fixed effects specification of the above model, intended to account for unobserved heterogeneity in worker productivity and other characteristics, are available from the authors. Findings for the referred and nonreferred salary trajectories are qualitatively similar to the estimates reported in Table 6 .

${ }^{31}$ Note this figure is based on specification (3) in Table 6. Confidence intervals are generated using the delta method. Appendix Figure A1 offers an alternative depiction of the trajectory of the referral salary advantage with tenure. It is based on the Table 6 column (2), in which the referral effect is estimated separately for each six month increment to tenure. Implications are similar.
} 
vs. non-referred hires. A valuable innovation in the theory of labor market referrals, then, might be an extension of existing models that accounted for these observed patterns. ${ }^{32}$

Finally, it is also evident in Figure 1 that all employees of the corporation enjoy a steep salary increase with tenure, which appears to be the dominant feature of salary trajectories in this corporation for both worker categories. It may be worth noting that an increasing wage trajectory is the central prediction of Jovanovic and other learning models. ${ }^{33}$

Our inability to measure performance-based pay may be particularly relevant to the analysis of salary dynamics. Though it is unlikely to influence initial salary comparisons, performance-based pay that behaves differently over time for referred and non-referred workers could meaningfully alter our conclusions regarding referred and non-referred salary convergence. The relevance of this measurement problem is closely tied to salary grade. However, to the extent that performance pay and promotion behave similarly in this firm, our results below regarding the relative promotion rates of referred and non-referred workers help alleviate the performance pay concern.

\section{Prediction 4: Turnover is lower for referred workers}

Next we turn to the theoretical prediction, reviewed in Section 3.1, that referred workers experience lower rates of turnover after joining a firm. We model separation from the corporation using the discrete time proportional hazard framework found in Prentice and Gloeckler (1978) and Meyer (1990). The instantaneous separation hazard at tenure $\tau$ is

$$
\lambda_{i \tau}^{D}=\lambda_{0}^{D}(\tau) \exp \left(Z_{i \tau}^{D} \delta^{D}\right)
$$

where $\lambda_{0}^{D}(\tau)$ is a baseline match dissolution hazard that is permitted to vary with tenure in the corporation and

$$
Z_{i \tau}^{D} \delta^{D}=\delta_{0}^{D} r_{i}+\delta_{1}^{D} \tau+\delta_{2}^{D} r_{i} \tau+\widetilde{Z}_{i \tau}^{D} \beta^{D}
$$

Here $\widetilde{Z}_{i \tau}^{D}$ includes company division and staff level, current shift, leave status, part time status, and in some specifications some subset of the interactions of starting staff level and the referral

\footnotetext{
${ }^{32}$ At the same time, such a finding is not inconsistent with a favoritism interpretation: if lower quality workers are hired through favoritism their quality may eventually be observed, leading to lower wages at longer tenures. Notice that this story would still have a learning element to it.

${ }^{33}$ Simon and Warner also find that scientists and engineers recollect lower salary growth in their ongoing jobs when they were referred, based on their 1972 survey data. They do not attempt to determine whether the lower salary growth leads non-referred workers' salaries to overtake referred workers' salaries at any point.
} 
indicator, an indicator for recession/post-recession dates and the interaction of the post-recession indicator with the referral indicator. We are primarily interested in the effect of referral on the separation hazard, and any variation in the referral effect on separation as tenure increases.

Table 7 reports estimates of hazard model (3) for separations in columns 1 to 3 . The reported estimates assume tenure dependence $\lambda_{0}^{D}(\tau)$ to be linear. ${ }^{34}$ In addition, the estimated values reported in Table 7 are in terms of $\exp (\delta)$, for ease of interpretation. Where the regressor is an indicator variable, given $(3)$, the reported $\exp (\delta)$ value can be interpreted as the proportional change in the hazard associated with moving from a regressor value of zero to a regressor value of one. This is measured relative to a baseline hazard, which represents the separation hazard of a full time, day shift, not on leave, mid-level, non-referred employee who has just entered the corporation during the pre-recession period. ${ }^{35}$ Table 7 estimates indicate that referred workers do indeed experience lower separation rates. Our baseline specification (1) shows that referred workers are only about 84 percent as likely to leave the corporation as non-referred workers, and this finding approaches significance at the five percent level. ${ }^{36}$

One might be concerned, given the predicted and observed tenure differential between referred and non-referred workers, that estimates of the salary dynamics of retained workers would reflect confounding dynamic selection effects. It may be helpful to note at this point that the goal of the salary trajectory estimates in Section 5.1 is to test the equilibrium predictions of models like Dustmann et al. and Simon and Warner. Therefore, in the empirical exercise we do not need to correct our salary trajectory estimates for differential attrition, as the model predictions are predicated on differential turnover. Hence our estimates of the salary trajectories of retained employees are, arguably, the appropriate objects with which to test these predictions. Importantly, and consistent with theory, when we control for differential separation among referred and nonreferred workers, initial salary differences are much more muted: see Figure A2 in the Appendix,

\footnotetext{
${ }^{34}$ We specify the tenure dependence of baseline hazard $\lambda_{0}^{D}(\tau)$ in two different ways. We have estimated the specifications in Table 7 with both linear and fully nonparametric assumptions on the baseline hazard, in the sense of including separate dummies for each observed six month interval with the corporation, and our qualitative results are essentially unchanged.

${ }^{35}$ For example, the $\exp (\delta)$ value in specification (1) associated with an on leave worker indicates that, perhaps not surprisingly, a worker currently on leave faces roughly three times the separation hazard of an employee who is not currently on leave, all else equal.

${ }^{36}$ Simon and Warner find that scientists and engineers in their 1972 retrospective survey recall longer job duration when they were referred, all else equal. Datcher (1983) also finds lower turnover in referred jobs, using PSID data. Additional results regarding the referral turnover effect are discussed in the appendix.
} 
which plots salary slopes for employees who stay at the corporation at least five years.

Prediction 5: The referred turnover advantage also diminishes over time

The significant negative association between employee referrals and separation from the corporation does not appear to diminish with tenure, despite the predictions of learning-based models but consistent with general productivity homophily models. In Table 7, specification (2) adds a referral indicator times tenure regressor to the estimation, and based on the specification (2) estimates we see that the separation hazard increment associated with referral does not appear to change in any noticeable way with tenure. Despite the (reasonably intuitive) theoretical prediction that the lower departure rates for referred workers diminish over time as the surviving non-referred workers become a more selected and better-matched group, the empirical results indicate that, for this corporation at least, the decreased separation rate associated with employee referrals is relatively long-lasting.

\section{Prediction 6: Referred workers have higher expected productivity}

The theoretical predictions of the learning and homophily models generally emphasize higher expected productivity for workers hired through referrals than for workers not hired through re-

ferrals. On the other hand, the monitoring and favoritism models tend to predict lower expected productivity for referred workers.

Though both worker productivity and employers' inferences regarding workers' productivity are difficult to measure, an employer's promotion decisions may offer a source of information on perceived worker effectiveness. It would be preferable to have performance review data, as in Kahn and Lange (2010), for example, but these are not currently available. Fredericksen, Lange, and Kriechel (2012), however, demonstrate a positive correlation between performance ratings and promotions in each of six large firms.

One major concern regarding the use of promotions to measure productivity is that, under favoritism, referred workers may be promoted through the influence of their referral providers, and not based on productivity. Hence, while slower or similar promotion rates for referred employees may provide credible evidence that referred workers do not have a decisive productivity advantage, 
evidence of a higher promotion rate among referred workers is insufficient to distinguish between favoritism and higher productivity.

We model the promotion process using approximately the same approach we applied to the tenure process above. In the discrete time proportional hazard framework we apply, the instantaneous promotion hazard is assumed to be

$$
\lambda_{i \tau}^{P}=\lambda_{0}^{P}(\tau) \exp \left(Z_{i \tau}^{P} \delta^{P}\right)
$$

where $\lambda_{0}^{P}(\tau)$ is a baseline promotion hazard that we again allow to vary either linearly or completely non-parametrically with tenure in the organization. This time

$$
Z_{i \tau}^{P} \delta^{P}=\delta_{0}^{P} r_{i}+\delta_{1}^{P} \tau+\delta_{2}^{P} r_{i} \tau+\widetilde{Z}_{i \tau}^{P} \beta^{P}
$$

with $\widetilde{Z}_{i \tau}^{P}$ including company division and staff level, current shift, leave status and part time status, and, in some specifications, some subset of the interactions of starting staff level and the referral indicator, an indicator for recession/post-recession dates and the interaction of the recession/postrecession indicator with the referral indicator. Unlike separations as measured in our data, promotions may arrive more than once for some employees. Our model admits repeated "failures", and second and later promotions do contribute to the reported coefficient estimates. We are primarily interested in the effect of referral on the promotion hazard, and any variation in the referral effect on promotion as tenure increases.

Table 7 reports the promotion model estimates in columns 4 to 6 . Looking first at our baseline specification in column (4), we find that referred employees are 92 percent as likely to be promoted over a given interval as non-referred employees, all else equal. ${ }^{37}$ This difference is not statistically significant at standard levels. So, despite the predictions of higher initial perceived productivity that arise from learning and homophily models, we cannot reject the hypothesis of equal promotion rates for the referred and non-referred, and, if anything, referred employees achieve promotion slightly more slowly than their non-referred peers. Instead, other employee characteristics appear to drive promotion, and these are discussed in the appendix to the paper.

\footnotetext{
${ }^{37}$ Note that, once again, results are robust to semi-parametric specification of the tenure dependence of the hazard.
} 
Turning to specification (5), we find no significant difference in the tenure dependence of promotion rates between the referred and non-referred. Theoretical predictions regarding whether the initial higher productivity of referred workers would be sustained are unclear. In any case, the data for this corporation do not support a meaningful difference in employers' promotion decisions for referred and non-referred workers over time.

Prediction 7: The variances of referred and non-referred workers' wages converge over time

Figure 2 shows the trajectories of referred and non-referred salary residual variances based on yearly salary regressions in levels. These are depicted from the hire date through 7 years of tenure, along with 95 percent confidence bands around the variance trajectories. We find that the referred salary variance lies below the non-referred salary variance, with (approximately) non-overlapping confidence bands, for each of the first four years. This finding aligns with the predictions of Datcher (1983). At five years the referred variance rises toward the non-referred variance, and their confidence intervals intersect. By seven years the residual salary variances of referred and nonreferred workers are approximately identical. Thus the data for this firm are consistent with our conjecture that salary variances for referred and external market workers converge over time. ${ }^{38}$ Note that this type of wage variance convergence is peculiar to the learning model, along with the "job shopping" model of Datcher. It is difficult to imagine a model of referred worker ability advantage that generates similar wage variance convergence. Further, the observed variance convergence is at odds with the prediction of the moral hazard model, which generates wage variance for referred workers that increases with tenure relative to non-referred.

\section{Prediction 8: The referral effect decreases with the skill level of the job market}

There is strong empirical evidence that informal search methods are used more by workers with lower socioeconomic status and lower education levels, and for 'lower-status' jobs. ${ }^{39}$ However, there is very limited work on the effect of referrals on outcomes by skill or education level. Using

\footnotetext{
${ }^{38}$ The observed salary variances are roughly consistent with the increasing pattern documented by Kahn and Lange (2010), for both referred and non-referred workers.

${ }^{39}$ Corcoran et al. (1980), Datcher (1983), Marx and Leicht (1992), all report higher usage for less educated job seekers. Elliot (1999) finds that informal contacts are more frequently used in high-poverty neighborhoods than in low-poverty ones. Rees and Schultz (1970) and Corcoran et al. (1980) both find that informal search methods are used more often for blue-collar than for white-collar occupations.
} 
an indirect approach, Topa (2001) studies the magnitude of referral effects across neighboring census tracts in Chicago. He finds that the estimated spillover effects are stronger in tracts with lower education levels and with higher fractions of minorities. Using a different identification strategy to identify neighborhood effects in labor market outcomes, Bayer et al. (2008) find that the estimated referral effects are stronger for less educated workers, younger workers, and Asian or Hispanic workers. The learning model of referrals in Galenianos (2013) includes predictions for the varying roles of referrals at high and low productivity firms. Presuming an association between firm productivity and employee skill in equilibrium, the Galenianos model can be interpreted to predict more prevalent referral use in low skill job markets, and a larger difference in wages and separation rates between referred and external workers at lower skill jobs.

The range of positions available in our data allows us to make some inferences regarding differences in the role of employee referrals across the markets for different employee skill levels. In the interest of studying the role of referrals in lower and higher skilled labor markets, we introduce education requirement-referral (or staff level-referral) interactions in the hiring, salary, promotion, and turnover models above.

Looking first at the applicant data, Table 8 reports estimates of expression (1) in which we have added education requirement and referral interactions. The main finding is that referrals have a significantly greater impact on the overall probability of interview receipt (or offer receipt conditional on interview) for positions with lower education requirements. Applicants to postings requiring high school diplomas and other educational credentials show significantly larger referral effects on interview probability than applicants to postings requiring college and graduate degrees. The additional effect of referral for high school and other requirement postings relative to college postings is 21 and 11 percentage points, respectively. Similarly, conditional on interview, applicants to positions requiring associate's degrees are 33 percentage points more likely to receive an offer than for college postings. ${ }^{40}$ These results are qualitatively consistent with those in Topa (2001) and Bayer et al. (2008).

Turning now to the employee log earnings regressions (reported in Table 10, column (2)), analysis of referral effects by staff level reveals a roughly similar (although non-monotonic) pattern.

\footnotetext{
${ }^{40}$ Regressions that include staff level-referral interactions indicate similar qualitative patterns by staff level, but they are not statistically significant.
} 
Support staff experience a particularly strong salary referral advantage relative to mid-level staff. Junior staff, senior staff, and executives show significantly lower initial salary referral advantages than other staff levels. On net, the estimated referral advantage is 8.6 and 3.4 percent of initial salary for support and mid-level staff, respectively. Junior staff have a net referral advantage of only about 0.9 percent of initial salary. More strikingly, the net referral effect on initial salary for executives is -4.5 percent relative to non-referred executives, and it is significantly different from zero.

Returning to the separation results in Table 7, we find that the negative separation effect of referral we observe for the full sample appears to be largest among the support staff. The Table 7 column (3) point estimates for the referral, the support staff, and the referral times the support staff indicators together indicate that referred support staff are only thirteen percent as likely to leave the corporation as non-referred mid-level staff. ${ }^{41}$ Put differently, being a referred support staff member is associated with an 87 percent decline from the baseline (mid-level non-referred) hazard. Further, the association between referral and the probability of separation increases roughly monotonically in staff level, going from a large negative association at the support staff level to a large positive association for executives. However, the effects of referral on the separation rates of junior and senior level staff are estimated to be extremely similar to the effects of referral on the separation rates of mid-level staff. ${ }^{42}$ Within each of these three groups, referral is associated with a decrease in the non-referred separation hazard of roughly 13 to 14 percent.

Echoing the results for initial salary, executives also demonstrate a unique referral-tenure relationship. We find that referred executives are substantially more likely to leave the corporation than non-referred mid-level staff. Based on the point estimates, referred executives are more than twice as likely to leave as non-referred mid-level staff. However, as a result of the relatively small sample of referred executives, this difference is not quite significant at conventional levels. ${ }^{43}$

In sum, employee referrals are used significantly more in filling lower skill positions. They are associated with strong positive tenure effects for lower skilled workers. For most rank-and-file

\footnotetext{
${ }^{41}$ This estimate is significant at standard significance levels.

${ }^{42}$ The differences among the referral effects on the non-referred separation hazards for junior, mid-level, and senior staff are, in all cases, insignificant.

${ }^{43}$ Regarding the promotion results in Table 7 , we observe no significant differences between referred and nonreferred promotion rates by staff level. In general, promotion practices appear to be quite similar for the referred and the non-referred.
} 
workers they also tend to be associated with higher starting salaries. The hiring, wage and tenure results appear to confirm predictions of Galenianos (2013) regarding the prevalence and evident impact of referrals for low skill positions. However, referrals appear to function quite differently in the market for executives. Their referrals are associated with, if anything, shorter-lived matches and lower starting salaries. Our estimates clearly indicate different roles for referrals across markets for different worker skill levels. ${ }^{44}$

\section{Summary}

Table 1 summarizes the eight theoretical predictions considered above, the models generating each prediction, and whether the empirical evidence generated by this study is consistent with the prediction. In sum, the empirical evidence aligns with the broad prediction of the theoretical literature that referred workers are both more likely to be hired and less likely to separate from the firm. Initial wages for the referred are significantly higher, confirming a shared prediction of learning and homophily models of referral. The diminishing referred worker wage advantage and the wage variance convergence we observe arguably favor the match-specific nature of referrals in the learning and modified homophily models described above. However, the lack of evidence of a diminishing turnover advantage over time for referred workers is generally consistent with a homophily-based but not a learning-based interpretation of referrals. Finally, insofar as promotions reflect observed productivity, the finding that promotions do not occur significantly faster for referred than nonreferred is not prima facie consistent with (simple versions of) any of the models considered here.

\subsection{Referral match analysis}

If referrals are used to replicate existing worker characteristics via homophily, then referrals from more productive or more senior employees may lead to better hires. Alternatively, if referrals are used to reduce noise in a signal of match quality, as in the learning model, then referrals from better informed employees may be preferable. Employees may be better informed regarding a candidate's suitability if they are more senior and hence have a better understanding of the sort of skills that are required to succeed in the organization, or if they are more similar to the candidate

\footnotetext{
${ }^{44}$ One important caveat is that, as noted above, we have relatively few observations for executives in our sample. Further, some of our results - for instance on the negative association between referrals and job tenure for executives - seem to be driven mostly by the post-recession period.
} 
and hence better able to evaluate him or her. In this Section we investigate whether different degrees of similarity between referral provider and receiver along various observable dimensions are associated with different referral effects, in terms of the various theoretical predictions we have studied. We first look at some descriptive measures of the degree of similarity between referrer and referred, and then consider salary levels and trajectories, and separation and promotion hazards.

Table 9 reports the degree of similarity between referral providers and receivers along the dimensions of gender, ethnicity, corporate division, age, staff level, and education. The majority of referral matches are between people of the same gender (63.5\%), the same race or ethnicity (71.5\%), and the same division (73.2\%), indicating a high degree of homophily in referrals. In the interest of confidentiality, the corporation prefers not to provide us with explicit demographics for individual employees. Referral match measures, therefore, indicate only whether provider and recipient share the same characteristic. Thus we are unable to compare, for example, the degree of similarity of referral pairs in the data to the degree of similarity that would result by random matching among a hiring pool and employee pool that resemble the demographics of the corporation's current employee pool. For confidentiality purposes, age comparisons were provided to us in 10 year brackets. ${ }^{45}$ In Table 9 we see that the distribution of providers' ages is slightly skewed towards older providers (younger receivers). Most referrals are provided by employees in higher (48.1\%) and in the same $(47.9 \%)$ staff levels. Only $4.1 \%$ of referrals came from lower level staff. Forty-nine percent of receivers are referred by providers with the same education level. The rest are referred by providers with more education $(17.6 \%)$, less $(11.2 \%)$, or an unknown education level $(22.5 \%) .{ }^{46}$

Table 10 column (3) reports the results of our log salary regressions, augmented by a set of dummy variables that describe the nature of the match between referral provider and receiver. ${ }^{47}$ We find that employees who received the referral from an older provider, someone in a higher staff level, someone in the same division, or someone who has been at the organization for less than two years have higher initial salaries than their counterparts. The magnitudes of the effects range from

\footnotetext{
${ }^{45}$ Specifically, we were given data indicating whether the provider and referred are within 10 year of the same age, the provider is 10 or more years older, or the provider is 10 or more years younger than the referred.

${ }^{46}$ Providers' tenure in the firm ranges from 0 to 11 years, with a mean of 3.1 years. Ten individuals in the sample were referred by two people. For these cases, we consider the referrer that is of the same gender, the same ethnicity, the same company division, older, a higher staff level, more educated, and with longer tenure.

${ }^{47}$ Note that we lack match variables on just over 1000 of our 12,443 employee-half year observations. Estimating the specification in column (1) on this subset does not change the qualitative results, and results in only very minor changes in the actual point estimates.
} 
an additional 1.8 percent salary advantage for referred workers when the referrer is in the same division, to a 4.8 percent additional salary advantage when the referrer is in a higher staff level. ${ }^{48}$

The age, staff level and division results are consistent with conjecture based on both the homophily and learning model at the start of this subsection. At the same time, it is also possible that these sorts of providers can exert more influence and secure a higher initial salary for the referred worker, consistent with a "favoritism" interpretation of referrals. The result for tenure is also interesting: it may indicate that workers who have spent relatively less time at the corporation have better connections with the outside labor market and are better able to provide referrals for workers who are good matches for the organization. ${ }^{49}$

We are also interested in seeing how these different provider-receiver matches affect the salary slope of referred employees over time. In Figure 3 we report salary slopes for different types of matches. The age, staff level and tenure results are consistent with those described above for initial salary. Furthermore, the initial salary advantage for those who were referred by an older provider, by someone in a higher staff level, or by someone with relatively short tenure actually persists longer than the average effect found in Figure 1, especially with regard to staff level and tenure. This finding would seem consistent with a homophily model of referrals.

The salary slope by division match is interesting: although the initial salary advantage is greater for those referred by someone in the same division, this pattern is reversed after two years of tenure, with employees referred by someone in a different division enjoying a larger and persistent advantage after three or four years of tenure. This finding seems particularly important to distinguish between a learning or homophily story vs. a favoritism story. If the referral providers work in a different division of the organization, it is less likely that they are able to exert direct influence over the employee's salary progression during her stay at the company. Thus this is perhaps our cleanest piece of evidence against a favoritism interpretation of referrals. At the same time, the finding that the referral salary advantage is more persistent in this case is again consistent with a homophily model where referral providers choose to refer high quality workers. ${ }^{50}$ Finally, these findings on

\footnotetext{
${ }^{48}$ These results are qualitatively consistent with those in Datcher (2006). She looks at the wage effects of referrals for different types of referral providers, and finds that older workers (who typically have higher incomes) tend to provide referrals for jobs associated with higher wages.

${ }^{49}$ Detailed estimates of the relationship between referral match characteristics and salary trajectory are available from the authors.

${ }^{50}$ Datcher (1983) also finds evidence inconsistent with a "clout" theory of referrals, in which the referrer "can facilitate promotion, earnings opportunities, and receiving nonpecuniary benefits".
} 
wage trajectories for specific referrer-referee pairs seem difficult to reconcile with the monitoring model.

Table 11 reports the impact of referral matches on promotion and separation hazards. The only match characteristics that have a significant impact on the likelihood of promotion are age, race/ethnicity and staff level. Counter to our salary regressions, those who received a referral from an older employee are significantly less likely to be promoted. Therefore, while receiving referrals from older providers is associated with an initial salary advantage, it is also associated with a lower chance of promotion over time. Further, same race/ethnicity and higher staff level providers appear to be advantageous in promotion: referrals from someone of the same race/ethnicity are associated with a significantly faster promotion rate, and those who received a referral from someone in a lower staff level are much less likely to be promoted. Again, the staff level finding is consistent with recipients of referrals from higher staff levels being more productive (or better matches for the organization) as predicted by the learning and homophily models, but we cannot exclude a favoritism interpretation of the referral. With regard to separations, we do not find any significant effects of referral match characteristics on separation hazard.

Finally, we have explored whether referral providers are systematically different from other employees. In short, providers are more senior, have less tenure, draw higher salaries, and are more likely to be promoted. ${ }^{51}$ These findings seem more consistent with referrals being used by firms to reduce uncertainty about prospective hires (as in the learning or homophily models) rather than as the result of patronage. ${ }^{52}$

\section{Conclusion}

Our unique firm-level data on job candidate referrals and subsequent careers in the firm allow us to address a series of open questions in the literature on job market referrals. We find that, in one sizable, diverse U.S. corporation, referred candidates are more likely to be hired, and hired referred workers enjoy a wage advantage for their first three years on the job. They stay with the firm

\footnotetext{
${ }^{51}$ Burks et al. (2013) find very similar patterns in their sample of nine firms. Hensvik and Skans (2013) use Swedish administrative data to infer referral links based on shared work histories between new hires and incumbents at a given firm. They also find similar patterns and evidence of a positive association between entrants' and incumbents' ability, consistent with homophily models a la Montgomery (1991).

${ }^{52}$ More detail on referral providers' employment characteristics and trajectories is available from the authors.
} 
longer, and their salary variance converges to that of non-referred workers over time. Each of these results is consistent with the predictions of established labor market referral models, particularly those that view the distinction between referred and non-referred workers from the perspective of Jovanovic-style learning about match productivity. On the other hand, the lack of evidence of a diminishing turnover advantage over time for referred workers is generally consistent with a homophily-based but not a learning-based interpretation of referrals. The results on wage levels and variances as a function of tenure seem to run counter to the moral hazard model.

We also find that employee referrals are used significantly more in filling lower skill positions, and are associated with significantly stronger tenure and initial salary effects for lower level positions. These hiring, salary and tenure results are broadly consistent with predictions in Galenianos (2013) regarding the prevalence and impact of referrals for low skill positions. They are also consistent with other findings in the empirical literature on referrals, such as Topa (2001) and Bayer et al. (2008).

Our analysis of the different types of referral matches (between referrer and referred) yields some additional insights. We find that referrals from employees that are older, in a higher staff level, or with relatively low tenure at the firm are associated with stronger salary advantages that tend to persist longer than average with tenure. These findings seem consistent with both a learning and a homophily story, where more senior or better informed employees may refer better quality new hires or reduce the noise around a new hire's match quality. In addition, referral providers from a different division than the recipient are associated with a steeper salary slope. The tenure and division results in particular are difficult to reconcile with a favoritism interpretation of referrals.

One would like to make some inference regarding whether referrals are good for firms and workers. Though we believe that our data offer a considerably more complete picture of the behavior of referrals than was previously available, at least for one sizable and diverse U.S. corporation, we do not have access to exogenous variation in workers' referral status. (It is difficult to imagine a source of such variation in standard labor market contexts.) As a result, we cannot make causative claims about the impact of job referrals. What we have done so far is to test the equilibrium predictions of leading models of labor market referrals, as well as to enrich economists' descriptive understanding of the behavior of referrals by provider-recipient relationship and across skill levels. Our results, by and large, tend to support the predictions of learning-based models of labor market referrals. Such 
models, for example Dustmann et al. and Simon and Warner, predict that referred candidates are hired in equilibrium only where such hires increase total surplus to the firm and worker. While we cannot claim to have demonstrated, in a direct sense, a positive effect of referral on wages or firm profits, we can say that our results support a family of models that predict worker-firm surplus gains from the use of referrals. 


\section{References}

[1] Aslund, Olof and Oskar Nordstrom Skans (2010): "Will I See You at Work? Ethnic Workplace Segregation in Sweden 1985-2002", Industrial and Labor Relations Review, 63 (3), 471-493

[2] Bayer, Patrick, Stephen L. Ross and Giorgio Topa (2008): "Place of work and place of residence: informal hiring networks and labor market outcomes," Journal of Political Economy 116 (6), 1150-1196.

[3] Beaman, Lori and Jeremy Magruder (2012): "Who Gets the Job Referral? Evidence from a Social Networks Experiment," American Economic Review, 102 (7), 3574-3593.

[4] Burks, Stephen V., Bo Cowgill, Mitchell Hoffman, and Michael Gene Housman (2013). "The Facts About Referrals: Toward and Understanding of Employee Referral Networks." SSRN working paper, http://papers.ssrn.com/sol3/papers.cfm?abstract_id=2253738 (last visited $2 / 27 / 14)$.

[5] Castilla, Emilio (2005): "Social networks and employee performance in a call center," American Journal of Sociology 110 (5), 1243-1283.

[6] Corcoran, Mary, Linda Datcher and Greg Duncan (1980): "Information and Influence Networks in Labor Markets," in Five Thousand American Families: Patterns of Economic Progress, edited by Greg Duncan and James Morgan, vol. 7, 1-37, Ann Arbor, MI: Institute For Social Research.

[7] Datcher, Linda. (1983): "The Impact of Informal Networks on Quit Behavior," The Review of Economics and Statistics, 65 (3), 491-495.

[8] Datcher Loury, Linda. (2006): "Some Contacts are More Equal than Others: Informal Networks, Job Tenure, and Wages," Journal of Labor Economics, 24 (2), 299- 318.

[9] Dustmann, Christian, Albrecht Glitz and Uta Schoenberg (2011): "Referral-based job search networks," manuscript, University College London.

[10] Elliot, James (1999): "Social Isolation and Labor Market Insulation: Network and Neighborhood Effects on Less-Educated Urban Workers," The Sociological Quarterly, 40 (2), 199-216.

[11] Fernandez, Roberto M., and Emilio J. Castilla (2001): "How Much Is That Network Worth? Social Capital Returns for Referring Prospective Hires," Pp. 85-104 in Social Capital: Theory Research, edited by Karen Cook, Nan Lin, and Ronald Burt.Hawthorne, N.Y.: Aldine De Gruyter.

[12] Fernandez, Roberto M., Emilio J. Castilla, and Paul Moore (2000): "Social Capital at Work: Networks and Employment at a Phone Center." American Journal of Sociology, 105 (5): 12881356.

[13] Fernandez, Roberto M. and Roman V. Galperin (2012): "The Causal Status of Social Capital in Labor Markets" forthcoming in Research in the Sociology of Organizations Volume on "Contemporary Perspectives on Organizational Social Network Analysis" edited by S.P. Borgatti, D.J. Brass, D.S. Halgin, G. Labianca, and A. Mehra, LINKS Center for Social Network Analysis. 
[14] Fernandez, Roberto and Nancy Weinberg (1997): "Sifting and sorting: personal contacts and hiring in a retail bank," American Sociological Review 62, 883-902.

[15] Frederiksen, Anders, Fabian Lange, and Ben Kriechel (2012): "Subjective Performance Evaluations and Employee Careers," manuscript, Yale University.

[16] Galenianos, Manolis (2013): "Learning About Match Quality and the Use of Referrals," Review of Economic Dynamics, 16 (4), 668-690.

[17] Galenianos, Manolis (2012): "Hiring Through Referrals," manuscript, Royal Holloway.

[18] Gee, Laura Katherine and Jason Jones (2012): "Social Networks and Labor Markets: How Strong Ties Relate to Job Transmission Using Facebook's Social Network," manuscript, University of California, San Diego.

[19] Giuliano, Laura, David I. Levine, and Jonathan Leonard (2009): "Manager Race and the Race of New Hires", Journal of Labor Economics, 27(4), 589-631

[20] Granovetter, Mark S. (1973): "The Strength of Weak Ties", American Journal of Sociology, Vol. 78 (6), 1360-1380.

[21] Heath, Rachel (2013): "Why do Firms Hire using Referrals? Evidence from Bangladeshi Garment Factories", manuscript, University of Washington.

[22] Hellerstein, Judith, Melissa McInerney, and David Neumark (2011): "Neighbors and Coworkers: The Importance of Residential Labor Market Networks", Journal of Labor Economics, 29 (4), 659-695.

[23] Hensvik, Lena and Oskar Nordstrom Skans (2013). "Social Networks, Employee Selection and Labor Market Outcomes," working paper, IFAU, http://www.ifau.se/en/Research/Publications/Working-papers/2013/Social-networksemployee-selection-and-labor-market-outcomes (last visited 2/28/14).

[24] Holzer, Harry J. (1987a): "Informal Job Search and Black Youth Unemployment," The American Economic Review, 77 (3), 446-452.

[25] Holzer, Harry J. (1987b): "Hiring Procedures in the Firm: Their Economic Determinants and Outcomes", in Human Resources and the Performance of the Firm, edited by Morris M. Kleiner, Richard N. Block, Myron Roomkin, and Sidney W. Salsburg, Madison, WI: Industrial Relations Research Association.

[26] Holzer, Harry J. (1988): "Search Method Use by Unemployed Youth," Journal of Labor Economics, 6 (1), 1-20.

[27] Ioannides, Yannis M. and Linda Datcher Loury. (2004): "Job Information Networks, Neighborhood Effects, and Inequality," Journal of Economic Literature, 42 (4), 1056-1093.

[28] Jovanovic, Boyan. (1979): "Job Matching and the Theory of Turnover," Journal of Political Economy 87, October: 972-90.

[29] Jovanovic, Boyan. (1984): "Matching, Turnover, and Unemployment," Journal of Political Economy 92, February: 108-22. 
[30] Kahn, L. and F. Lange (2010): "Learning about Employee and Employer Learning: Dynamics of Performance and Wage Measures", manuscript, Yale University.

[31] Kramarz, Francis and Oskar Nordstrom Skans (2013): "When Strong Ties are Strong: Networks and Youth Labor Market Entry", Review of Economic Studies, forthcoming.

[32] Kugler, Adriana (2003). "Employee Referrals and Efficiency Wages," Labour Economics, 10 (5) 531-556.

[33] Ljungqvist, Lars and Thomas J. Sargent (2000), Recursive Macroeconomic Theory, Cambridge, MA: The MIT Press.

[34] Marsden, Peter V. (1987): "Core Discussion Networks of Americans",American Sociological Review, Vol. 52, pp. 122-131.

[35] Marsden, Peter V. (1988): "Homogeneity in Confiding Relations", Social Networks, Vol. 10, pp.57-76.

[36] Marsden, Peter V. (2001): "Interpersonal Ties, Social Capital, and Employer Staffing Practices", in Social Capital: Theory and Research, edited by Nan Lin, Karen Cook and Ronald S. Burt, New Brunswick, NJ: Transaction Publishers.

[37] Marsden, Peter V. and Elizabeth H. Gorman (2001): "Social Networks, Job Changes and Recruitment", in Sourcebook on Labor Markets: Evolving Structures and Processes, edited by Ivar Berg and Arne L. Kalleberg, New York, NY: Kluwer Academic/Plenum Publishers.

[38] Marx, Jonathan and Kevin T. Leicht (1992): "Formality of Recruitment to 229 Jobs: Variation by Race, Sex and Job Characteristics", Sociology and Social Research, Vol. 76, 190-196.

[39] Meyer, B.D. (1990): "Unemployment insurance and unemployment spells", Econometrica, $58(4), 757-782$.

[40] Montgomery, James D. (1991): "Social Networks and Labor-Market Outcomes: Toward an Economic Analysis", American Economic Review, 81(5), 1407-18.

[41] Oyer, Paul and Scott Schaefer (2012): "Firm/Employee Matching: An Industry Study of American Lawyers", NBER Working Paper 18620.

[42] Pallais, Amanda and Emily Glassberg Sands (2013), "Why the Referential Treatment? Evidence from Field Experiments on Refereals," Harvard University, working paper, https://bepp.wharton.upenn.edu/bepp/assets/File/AE-F13-Pallais(1).pdf (last visited $2 / 28 / 2014)$.

[43] Pellizzari, Michele (2010). "Do Friends and Relatives Really Help in Getting a Good Job?" Industrial and Labor Relations Review, 63(3), 494-510.

[44] Prentice, R. and L. Gloeckler (1978): "Regression analysis of grouped survival data with application to breast cancer data," Biometrics, 34(1), 57-67.

[45] Rees, Albert and George Schultz (1970): "Workers and Wages in the Urban Labor Market". University of Chicago Press.

[46] Sargent, Thomas J. (1987), Dynamic Macroeconomic Theory. Cambridge, Mass.: Harvard University Press. 
[47] Simon, Curtis J. and John T. Warner (1992): "Matchmaker, Matchmaker: The Effect of Old Boy Networks on Job Match Quality, Earnings, and Tenure", Journal of Labor Economics, 10(3), 306-330.

[48] Topa, Giorgio (2001): "Social Interactions, Local Spillovers and Unemployment," Review of Economic Studies, vol. 68, no. 2, 261-295.

[49] Topa, Giorgio (2011): "Labor Markets and Referrals", in: Jess Benhabib, Alberto Bisin and Matthew O. Jackson (eds.), Handbook of Social Economics; Amsterdam: Elsevier North Holland. 


\section{A Additional Results}

A few more findings regarding the firm's hiring process and employees' experiences, though not of direct relevance to model predictions, may be of interest.

First, following Section 5.1, prediction 1, the Table 5 estimates of the probabilities of being interviewed and receiving an offer provide some ancillary information on the corporation's hiring process. Unsurprisingly, a larger number of applicants significantly increases the competitiveness of the position. However, the magnitude of this effect is small: 100 more applicants for a position are associated with a 0.1 percentage point decrease in the probability that an applicant is interviewed. Surprisingly, the proportion of applicants that are referred increases the likelihood that an applicant for the position receives either an interview or an offer, and this effect is significant. A 10 percentage point increase in the proportion referred is associated with a 0.88 percentage point increase in the probability of an interview, and a 0.44 percentage point increase in the probability of an offer.

Staff level coefficient estimates indicate that support staff positions are significantly less competitive than mid-level staff positions, but that junior, senior and executive level staff positions are comparably competitive to mid-level staff positions. Similarly, positions that require a high school diploma are significantly less competitive than positions that require a college degree, particularly at the interview stage, while associate's degree, college degree and other education requirement positions are similarly competitive. However, we do find that positions that require a graduate degree are significantly more competitive than positions that require a college degree, particularly at the interview stage.

Screening from the application to interview stage becomes stronger over time in our data, with the probability of being interviewed conditional on applying decreasing by 0.5 percentage points per year. Yet the probability of receiving an offer conditional on having been interviewed increases significantly over time, and the overall offer probability for applicants does not vary significantly over time. Finally, we see a lower probability for the applicant of being interviewed following the start of the recession, with, again, no significant change in the overall probability of an offer. Together these estimates suggest that screening resources are being shifted to earlier points in the hiring process over the course of the panel.

Applicants sourced from the corporate website and who applied through their own initiative 
have interview and offer rates similar to those of job board applicants. As hinted by the Table 4 transition rates, however, "other" applicants, including those produced by campus recruiting, have interview and offer probabilities that are significantly higher than those of job board applicants.

An interesting side question is whether the corporation views referrals as substitutes or complements to other inputs in the recruiting technology. We find some (weak) evidence of substitution between referrals and other inputs into the screening process: controlling for applicant pool size, the percentage of applicants who get interviews is negatively correlated with the presence of referrals in the pool.

Turning to Section 5.1's prediction 4, regarding the effect of referral on tenure in the corporation, we find that most of this referral effect arises from the pre-recession period. Pre-recession referred workers are 76 percent as likely to leave the organization as pre-recession non-referred workers, and this effect has a p-value of 0.045 . However, the referral effect on separations for those hired after the start of the recession is much more moderate. For people hired after 2007, referred workers are only 96 percent as likely to leave the corporation compared to non-referred people, and this difference is not statistically significant. Similarly, if one estimates using only the pre-recession sample, one finds that referred workers are 77 percent as likely to leave the corporation as non-referred workers, and the p-value for this estimate is 0.056. The period beginning with the recession was one of meaningful changes in employment practices for this particular corporation, as for many others. We find substantially decreased turnover from the start of the recession, and decidedly different hiring practices. Thus it is not surprising that employee referrals appear to function differently for this corporation from the start of the recession.

Despite our failure to identify a significant effect of referral on promotion under Section 5.1's prediction 6 , the Table 7 results on promotion are informative regarding which employee characteristics do drive promotion. Employees with longer tenure in the corporation are significantly more likely to be promoted. One year of tenure increases the promotion probability over the next six months by five percentage points, all else equal. Not surprisingly, full time, day shift, and active status workers are more likely to be promoted. The relationship between staff level and promotion rate is roughly monotonically decreasing. Junior staff are promoted at significantly higher rates than mid-level staff. Senior and executive staff are promoted at only 63 and 51 percent, respectively, of the rate of mid-level staff, and this difference is significant at the one percent level. Finally, the 
rate of promotions at this corporation increased following the start of the recession.

Finally, we have also run our empirical analysis separately for some of the largest divisions within the company, to see whether our results are robust to possibly different management practices within the company. Our findings are qualitatively very similar across the four largest divisions of the corporation, with some variation in the size of the estimated referral effects on outcomes. For instance, the estimated initial salary advantage for referred vs. non-referred workers ranges between 0.8 and 5.4 percent of initial salary across divisions. There is also some evidence in one division that referrals are associated to a higher promotion hazard, suggesting higher perceived productivity for referred hires. Overall, the results are remarkably similar across the entire corporation. 


\section{Table 1: Referral Model Predictions and Estimation Results}

\begin{tabular}{|c|c|c|c|c|c|}
\hline \multirow[b]{2}{*}{ Prediction } & \multicolumn{4}{|c|}{ Referral model } & \multirow[b]{2}{*}{ Data } \\
\hline & Learning & Homophily & Moral hazard & Favoritism & \\
\hline 1. $\operatorname{Pr}($ hire $)$ & 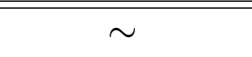 & $\overline{\bar{R} R>E}$ & $\overline{\bar{R} R>E}$ & $\overline{\bar{R} R>E}$ & 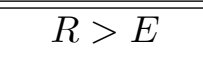 \\
\hline 2. Initial wages & $R>E$ & $R>E$ & $R<E$ or $\sim$ & $\sim$ & $R>E$ \\
\hline 3. Wage gap with $\tau$ & $\searrow$ & flat ${ }^{* * *}$ & $\nearrow$ & flat & $\searrow$ \\
\hline 4. Separation & $R<E$ & $R<E$ & $R<E$ & $\sim$ & $R<E$ \\
\hline 5. Separation gap with $\tau$ & $\searrow$ & flat*** & flat & $\sim$ & flat \\
\hline 6. Mean productivity & $R>E$ & $R>E$ & $R<E$ or $\sim$ & $R<E$ & $\begin{array}{l}R=E \\
\text { or } \sim * * * *\end{array}$ \\
\hline 7. Wage variance & $\begin{array}{c}R<E^{*} \text { or } \sim \\
\text { gap } \searrow \text { in } \tau\end{array}$ & $\sim$ & $\begin{array}{c}\sim, \\
\operatorname{gap} \nearrow \text { in } \tau\end{array}$ & $\sim$ & $\begin{array}{c}R<E, \\
\text { gap } \searrow \text { in } \tau\end{array}$ \\
\hline $\begin{array}{l}\text { 8. Referral effects by skill } \\
\text { level }\end{array}$ & $\searrow^{* *}$ & $\sim$ & $\sim$ & $\sim$ & $\searrow$ \\
\hline
\end{tabular}

$\overline{\mathrm{R}}=$ referral-sourced candidate, $\mathrm{E}=$ external market-sourced candidate; ${ }^{*}=$ Datcher $1983 . \tau$ =tenure.

**Among the learning models, this prediction emerges only from Galenianos (2013).

*** The table entry describes a model in which referral relationships are homophilous in general worker productivity. A model in which they are homophilous in firm-specific productivity would instead appear to lead to the declining wage and separation gaps predicted by learning models.

****Assuming promotion reflects productivity, our results indicate no significant productivity advantage for either referred or unreferred workers. However, if promotion does not reflect productivity, then our data do not allow us to test productivity predictions. 
Table 2: Estimation Sample Descriptive Statistics, Applicant Data

\begin{tabular}{rrrrr}
\hline \hline & \multicolumn{2}{c}{ Applicants, $N=62,127$} & \multicolumn{2}{c}{ Positions, $N=315$} \\
Characteristics & Observations & Proportion & Observations & Proportion \\
\hline Number of Interviews & 1,811 & $2.9 \%$ & & \\
Number of Offers & 428 & $0.7 \%$ & & \\
Number of Hires & 340 & $0.6 \%$ & & \\
Support Staff & 1,732 & $2.8 \%$ & 15 & $4.8 \%$ \\
Junior Staff & 30,685 & $49.4 \%$ & 123 & $39.1 \%$ \\
Mid-level Staff & 17,269 & $27.8 \%$ & 106 & $33.7 \%$ \\
Senior Staff & 11,398 & $18.4 \%$ & 64 & $20.3 \%$ \\
Executive & 1,052 & $1.7 \%$ & 7 & $2.2 \%$ \\
& & & & \\
. & 1,537 & $2.5 \%$ & 18 & $5.7 \%$ \\
Associates Degree Required & 935 & $1.5 \%$ & 6 & $1.9 \%$ \\
Bachelors Degree Required & 38,057 & $61.3 \%$ & 175 & $55.6 \%$ \\
Graduate Degree Required & 18,478 & $29.7 \%$ & 96 & $30.5 \%$ \\
Not Indicated or Other & 3,120 & $5.0 \%$ & 20 & $6.3 \%$ \\
\hline Yed & & & & \\
\hline
\end{tabular}

Years of Experience Required- mean: 5.3; median: 4; SD: 3.4; min: 1; max: 12

Number of Applicants for a Position- mean: 185.2; median: 113; SD: 245.2; min: 1; max: 2,283

Number of Interviews for a Position- mean: 6.7; median: 5; SD: 7.0; min: 1; max: 52

Notes: Jobs were posted between 2006 and 2010. Excluding one person pools \& postings that did not result in hires. 
Table 3: Estimation Sample Descriptive Statistics, Employee Data

\begin{tabular}{rrrrrr}
\hline \hline Characteristic & & & & & \\
Full Sample & 12,447 & $100 \%$ & Chique Individuals & 1,774 & $100 \%$ \\
\hline \hline Separations from firm & 638 & $5 \%$ & Referred & 509 & $29 \%$ \\
Promotions & 1,852 & $15 \%$ & Ever Promoted & 1,005 & $57 \%$ \\
& & & Ever Separated & 638 & $36 \%$ \\
Support Staff & 329 & $3 \%$ & & & \\
Junior Staff & 4,451 & $36 \%$ & Day Shift & 12,296 & $99 \%$ \\
Mid-level Staff & 5,108 & $41 \%$ & Graveyard Shift & 50 & $0 \%$ \\
Senior Staff & 2,253 & $18 \%$ & On leave & 194 & $1 \%$ \\
Executive & 306 & $2 \%$ & Part Time & 111 & $1 \%$ \\
& & & & & \\
Mean tenure in years & 3.01 & & Mean hires/year & 150.50 & 176.91 \\
Mean time to Promotion & 1.66 & & Mean promotions/year & 56.71 & \\
to first promotion & 1.62 & & Mean separations/year & & \\
\end{tabular}

Salary: mean: $\$ 102,740 ;$ median: $\$ 97,377 ;$ SD: $\$ 45,551$

Notes: Salary is reported in 2010 dollars. 
Table 4: Percent of Applicants at Each Stage by Method of Applying

\begin{tabular}{rrrrr}
\hline \hline Source & Applicant & Interview & Offer & Hired \\
\hline \hline Internet Job Board & 60.1 & 40.0 & 23.6 & 23.5 \\
Firm Website & 14.8 & 10.1 & 9.6 & 10.6 \\
Own Initiative & 10.1 & 7.7 & 7.0 & 5.6 \\
Other & 6.9 & 13.9 & 21.3 & 23.5 \\
Referred by Current Employee & 6.1 & 21.4 & 27.3 & 29.1 \\
Campus Recruitment & 2.1 & 6.9 & 11.2 & 7.6 \\
\hline Sum & 100.0 & 100.0 & 100.0 & 100.0
\end{tabular}

Total Sample: 62,127

Table 5: Linear Model of Interview and Offer Probability

\begin{tabular}{rccc}
\hline \hline & $(1)$ & $(2)$ & $(3)$ \\
& Interview & Offer & Offer/Interview \\
\hline \hline Referral & $0.073^{* * *}$ & $0.024^{* * *}$ & $0.139^{* * *}$ \\
& $(0.003)$ & $(0.001)$ & $(0.027)$ \\
Firm Website & -0.002 & -0.001 & 0.047 \\
& $(0.002)$ & $(0.001)$ & $(0.037)$ \\
Own Initiative & 0.000 & 0.001 & $0.071^{*}$ \\
& $(0.002)$ & $(0.001)$ & $(0.038)$ \\
Other Source & $0.042^{* * *}$ & $0.018^{* * *}$ & $0.173^{* * *}$ \\
& $(0.002)$ & $(0.001)$ & $(0.028)$ \\
\# Applicants/100 & $-0.001^{* * *}$ & $-0.000^{* * *}$ & $-0.011^{* *}$ \\
& $(0.000)$ & $(0.000)$ & $(0.005)$ \\
Share of Applicants & $0.087^{* * *}$ & $0.044^{* *}$ & $0.107^{*}$ \\
Referred & $(0.004)$ & $(0.002)$ & $(0.028)$ \\
R-squared & 0.037 & 0.021 & 0.082 \\
Observations & 62,127 & 62,127 & 1811 \\
\hline \hline
\end{tabular}

Notes: $* \mathrm{p} \leq 0.10,{ }^{* *} \mathrm{p} \leq 0.05, * * * \mathrm{p} \leq 0.01$. Standard errors in parentheses. Excludes job postings that did not result in hires and one person pools. Specification (3) only includes those who received interviews. Omitted category: Internet job posting, college required, mid-level staff. Controls include staff levels, required education categories, dummies for year of job posting, and a constant term. 
Table 6: Pooled Log Salary Regressions

\begin{tabular}{rccc}
\hline \hline & $(1)$ & $(2)$ & $(3)$ \\
\hline \hline Referral & $0.021^{* * *}$ & $0.023^{* * *}$ & $0.019^{* * *}$ \\
& $(0.005)$ & $(0.008)$ & $(0.006)$ \\
Tenure * Referral & $-0.009^{* * *}$ & & -0.005 \\
& $(0.001)$ & & $(0.004)$ \\
Tenure at Firm & $0.042^{* * *}$ & & $0.059^{* * *}$ \\
& $(0.001)$ & & $(0.002)$ \\
Support Staff & $-0.891^{* * *}$ & $-0.888^{* * *}$ & $-0.889^{* * *}$ \\
& $(0.009)$ & $(0.009)$ & $(0.009)$ \\
Junior Staff & $-0.451^{* * *}$ & $-0.450^{* * *}$ & $-0.451^{* * *}$ \\
& $(0.003)$ & $(0.003)$ & $(0.003)$ \\
Senior Staff & $0.343^{* * *}$ & $0.344^{* * *}$ & $0.344^{* * *}$ \\
& $(0.004)$ & $(0.004)$ & $(0.004)$ \\
Executive & $0.920^{* * *}$ & $0.921^{* * *}$ & $0.921^{* * *}$ \\
& $(0.009)$ & $(0.009)$ & $(0.009)$ \\
Tenure Squared/100 & & & $-0.209^{* * *}$ \\
& & & $(0.023)$ \\
Tenure*Referral & & & -0.058 \\
Squared /100 & & & $(0.046)$ \\
\hline R-squared & 0.861 & 0.863 & 0.863 \\
Observations & 12,443 & 12,443 & 12,443 \\
\hline \hline
\end{tabular}

Notes: $* \mathrm{p} \leq 0.10, * * \mathrm{p} \leq 0.05, * * * \mathrm{p} \leq 0.01$. Standard errors in parentheses. Omitted category is not referred, day shift, full time, not on leave, mid-level staff. Controls include company divisions, shift, full-time/part-time status, leave status, current half-year, and a constant term. Specification (1) includes a linear trend in tenure; specification (2) includes a dummy for each six months of tenure and interactions of referral with half-years of tenure; specification (3) includes a quadratic trend in tenure. 


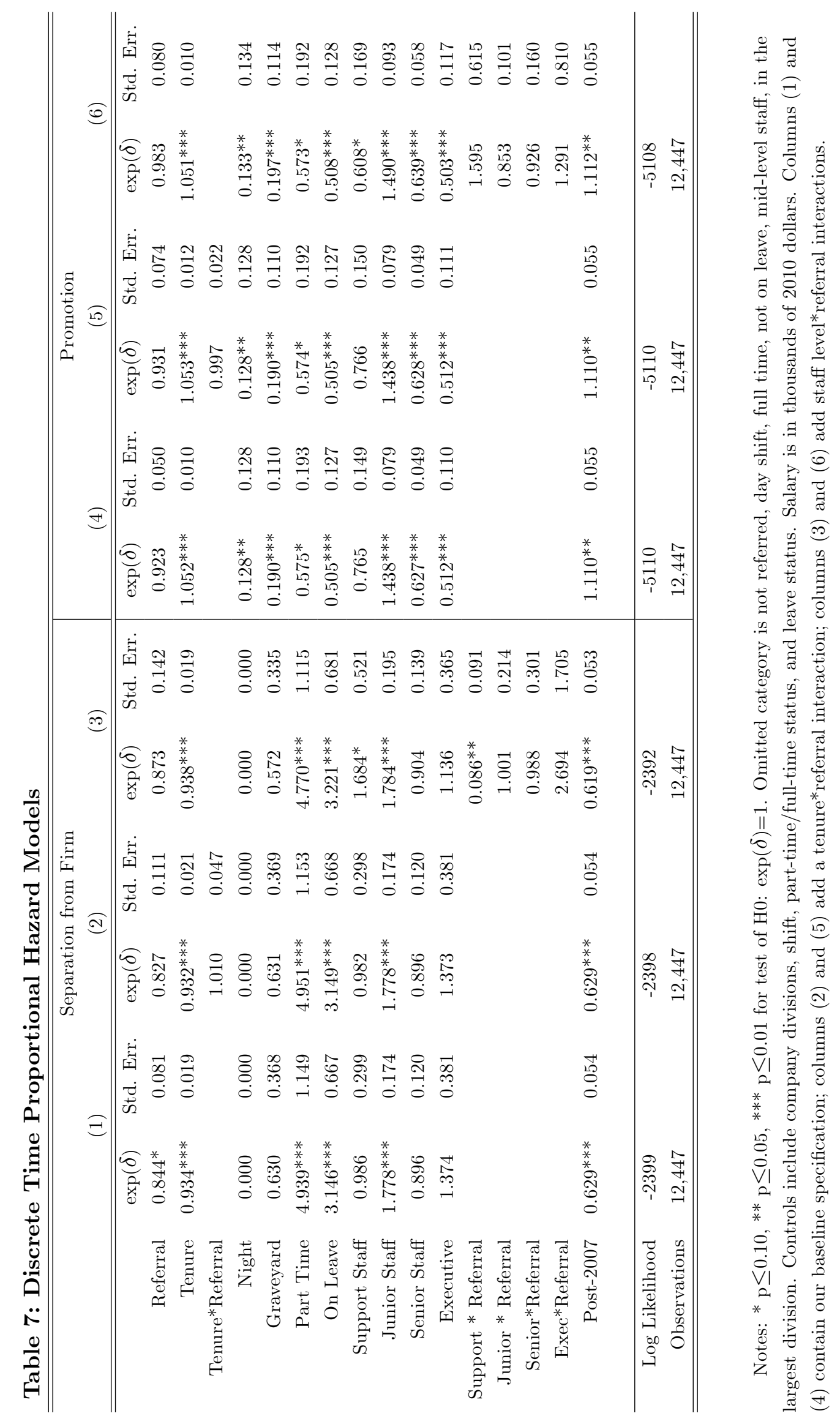


Table 8: Linear Model of Interview and Offer Probability - With Interactions

\begin{tabular}{|c|c|c|c|}
\hline & $\begin{array}{c}(1) \\
\text { Interview }\end{array}$ & $\begin{array}{c}(2) \\
\text { Offer }\end{array}$ & $\begin{array}{c}(3) \\
\text { Offer/Interview }\end{array}$ \\
\hline \multirow[t]{2}{*}{ Referral } & $0.058^{* * *}$ & $0.021^{* * *}$ & $0.155^{* * *}$ \\
\hline & $(0.008)$ & $(0.004)$ & $(0.037)$ \\
\hline \multirow{2}{*}{ Firm Website } & -0.003 & -0.001 & 0.052 \\
\hline & $(0.003)$ & $(0.001)$ & $(0.034)$ \\
\hline \multirow[t]{2}{*}{ Own Initiative } & -0.000 & 0.001 & $0.073^{* *}$ \\
\hline & $(0.002)$ & $(0.001)$ & $(0.036)$ \\
\hline \multirow[t]{2}{*}{ Other Source } & $0.041^{* * *}$ & $0.018 * * *$ & $0.174^{* * *}$ \\
\hline & $(0.007)$ & $(0.004)$ & $(0.039)$ \\
\hline \multirow[t]{2}{*}{ Support Staff } & 0.015 & 0.014 & 0.117 \\
\hline & $(0.021)$ & $(0.018)$ & $(0.124)$ \\
\hline \multirow[t]{2}{*}{ Junior Staff } & 0.003 & -0.000 & -0.019 \\
\hline & $(0.006)$ & $(0.002)$ & $(0.041)$ \\
\hline \multirow[t]{2}{*}{ Senior Staff } & 0.003 & -0.001 & -0.038 \\
\hline & $(0.005)$ & $(0.002)$ & $(0.031)$ \\
\hline \multirow[t]{2}{*}{ Executive } & -0.008 & 0.003 & 0.110 \\
\hline & $(0.013)$ & $(0.003)$ & $(0.094)$ \\
\hline Experience Required & $0.003^{* * *}$ & 0.000 & -0.010 \\
\hline (in years) & $(0.001)$ & $(0.000)$ & $(0.006)$ \\
\hline \multirow[t]{2}{*}{ High School Required } & 0.011 & 0.007 & 0.013 \\
\hline & $(0.013)$ & $(0.008)$ & $(0.072)$ \\
\hline Associates Degree & -0.016 & -0.012 & -0.041 \\
\hline req'd & $(0.025)$ & $(0.018)$ & $(0.190)$ \\
\hline Graduate Degree & -0.005 & -0.002 & -0.026 \\
\hline req'd & $(0.005)$ & $(0.002)$ & $(0.027)$ \\
\hline \multirow[t]{2}{*}{ Not Indicated / Other } & 0.001 & -0.002 & -0.045 \\
\hline & $(0.009)$ & $(0.005)$ & $(0.074)$ \\
\hline \multirow[t]{2}{*}{ High School ${ }^{*}$ Referral } & $0.212^{* * *}$ & 0.018 & -0.195 \\
\hline & $(0.067)$ & $(0.030)$ & $(0.121)$ \\
\hline \multirow[t]{2}{*}{ Associate $*$ Referral } & 0.011 & 0.040 & $0.328 * *$ \\
\hline & $(0.049)$ & $(0.053)$ & $(0.137)$ \\
\hline \multirow[t]{2}{*}{ Grad School * Referral } & 0.013 & 0.003 & -0.008 \\
\hline & $(0.014)$ & $(0.006)$ & $(0.055)$ \\
\hline \multirow[t]{2}{*}{ Other Req. ${ }^{*}$ Referral } & $0.114^{* *}$ & 0.030 & -0.030 \\
\hline & $(0.045)$ & $(0.021)$ & $(0.126)$ \\
\hline R-Squared & 0.040 & 0.022 & 0.086 \\
\hline Observations & 62,127 & 62,127 & 1811 \\
\hline
\end{tabular}

Notes: ${ }^{*} \mathrm{p} \leq 0.10,{ }^{* *} \mathrm{p} \leq 0.05,{ }^{* * *} \mathrm{p} \leq 0.01$. Standard errors in parentheses. Excludes job postings w/o hires \& 1 person pools. Column (3) includes only those who were interviewed. Omitted category: Internet postings, college required, mid-level staff. Controls include \# of applicants, proportion referred, dummies for year of job posting, \& a constant. 
Table 9: Characteristics of Providers and Receivers of Referrals

\begin{tabular}{|c|c|c|c|c|}
\hline Provider's & \% Same & \% Different & & \\
\hline Gender & 63.5 & 36.5 & & \\
\hline Ethnicity & 71.5 & 28.5 & & \\
\hline Division & 73.2 & 26.8 & & \\
\hline & $>10$ yrs. Older & Within 10 yrs. & $>10$ yrs. Younger & \\
\hline Age & 35.8 & 48.1 & 16.1 & \\
\hline & $\%$ Higher & $\%$ Same & $\%$ Lower & \\
\hline Staff Level & 48.1 & 47.9 & 4.1 & \\
\hline & $\%$ More & $\%$ Same & $\%$ Less & $\%$ Unknown \\
\hline Education & 17.6 & 48.7 & 11.2 & 22.5 \\
\hline \multirow{4}{*}{$\begin{array}{r}\text { Provider } \\
\text { Tenure }\end{array}$} & Mean & Range & Standard Dev. & \\
\hline & 3.1 years & $0-11$ years & 2.9 years & \\
\hline & Tenure 25th Pctile & Median & 75th Pctile & \\
\hline & 1 year & 2 years & 4 years & \\
\hline
\end{tabular}

Notes: Some referrals were dropped for missing provider data. Only 10 referees are referred by two people in our sample. For multiple providers of differing characteristics, we err on the side of matching provider and referrer characteristics, older provider age, higher staff level, and higher education. 
Table 10: Pooled Log Salary Regressions with Referral Matches

\begin{tabular}{|c|c|c|c|}
\hline & $(1)$ & $(2)$ & $(3)$ \\
\hline Referral & $\begin{array}{c}0.019^{* * *} \\
(0.006)\end{array}$ & $\begin{array}{c}0.034^{* * *} \\
(0.006)\end{array}$ & $\begin{array}{c}-0.048^{* * *} \\
(0.012)\end{array}$ \\
\hline Tenure ${ }^{*}$ Referral & $\begin{array}{l}-0.005 \\
(0.004)\end{array}$ & $\begin{array}{c}-0.010^{* * *} \\
(0.001)\end{array}$ & $\begin{array}{l}-0.008 \\
(0.006)\end{array}$ \\
\hline Tenure at Firm & $\begin{array}{c}0.059^{* * *} \\
(0.002)\end{array}$ & $\begin{array}{c}0.042^{* * *} \\
(0.001)\end{array}$ & $\begin{array}{c}0.059^{* * *} \\
(0.002)\end{array}$ \\
\hline Tenure Squared /100 & $\begin{array}{c}-0.208^{* * *} \\
(0.023)\end{array}$ & & $\begin{array}{c}-0.205^{* * *} \\
(0.023)\end{array}$ \\
\hline $\begin{array}{l}\text { Tenure Squared } \mathrm{x} \\
\text { Referral/100 }\end{array}$ & $\begin{array}{l}-0.058 \\
(0.046)\end{array}$ & & $\begin{array}{c}0.016 \\
(0.100)\end{array}$ \\
\hline Support Staff & $\begin{array}{c}-0.889^{* * *} \\
(0.009)\end{array}$ & $\begin{array}{c}-0.913^{* * *} \\
(0.012)\end{array}$ & $\begin{array}{c}-0.890^{* * *} \\
(0.010)\end{array}$ \\
\hline Junior Staff & $\begin{array}{c}-0.451^{* * *} \\
(0.003)\end{array}$ & $\begin{array}{c}-0.445^{* * *} \\
(0.004)\end{array}$ & $\begin{array}{c}-0.450^{* * *} \\
(0.003)\end{array}$ \\
\hline Senior Staff & $\begin{array}{c}0.344^{* * *} \\
(0.004)\end{array}$ & $\begin{array}{c}0.348^{* * *} \\
(0.005)\end{array}$ & $\begin{array}{c}0.344^{* * *} \\
(0.004)\end{array}$ \\
\hline Executive & $\begin{array}{c}0.921^{* * *} \\
(0.009)\end{array}$ & $\begin{array}{c}0.930^{* * *} \\
(0.010)\end{array}$ & $\begin{array}{c}0.929^{* * *} \\
(0.009)\end{array}$ \\
\hline Same Gender & & & $\begin{array}{l}-0.003 \\
(0.007)\end{array}$ \\
\hline Same Ethnicity & & & $\begin{array}{c}0.000 \\
(0.007)\end{array}$ \\
\hline Older Provider & & & $\begin{array}{c}0.041^{* * *} \\
(0.009)\end{array}$ \\
\hline Higher Staff Level & & & $\begin{array}{c}0.048^{* * *} \\
(0.007)\end{array}$ \\
\hline Same Division & & & $\begin{array}{r}0.018^{* *} \\
(0.007)\end{array}$ \\
\hline Provider Tenure $<$ Median & & & $\begin{array}{c}0.048^{* * *} \\
(0.006)\end{array}$ \\
\hline Provider More Educated & & & $\begin{array}{l}-0.015^{*} \\
(0.009)\end{array}$ \\
\hline Support Staff * Referral & & $\begin{array}{c}0.052^{* * *} \\
(0.019)\end{array}$ & \\
\hline Junior Staff $*$ Referral & & $\begin{array}{c}-0.025^{* * *} \\
(0.007)\end{array}$ & \\
\hline Senior Staff $*$ Referral & & $\begin{array}{c}-0.018^{* * *} \\
(0.009)\end{array}$ & \\
\hline Executive Staff $*$ Referral & & $\begin{array}{c}-0.079 * * * \\
(0.029)\end{array}$ & \\
\hline R-squared & 0.862 & 0.862 & 0.870 \\
\hline Observations & 12,443 & 12,443 & 11,363 \\
\hline \multicolumn{4}{|c|}{$\begin{array}{l}\text { Notes: }{ }^{*} \mathrm{p} \leq 0.10,{ }^{* *} \mathrm{p} \leq 0.05,{ }^{* * *} \mathrm{p} \leq 0.01 . \text { Controls include company divisions, } \\
\text { shift, leave status, full-time/part-time status, and a constant term. Column (1) } \\
\text { reports the same specification as in Table } 6 \text { column (3); column }(2) \text { adds staff } \\
\text { level*referral interactions; column }(3) \text { adds referral* provider type interactions. }\end{array}$} \\
\hline
\end{tabular}




\section{Table 11: Referral effects on promotion and separation by referral match}

\begin{tabular}{|c|c|c|c|c|c|c|c|c|}
\hline & \multicolumn{4}{|c|}{ Promotions } & \multicolumn{4}{|c|}{ Separations } \\
\hline & \multicolumn{2}{|c|}{$(1)$} & \multicolumn{2}{|c|}{$(2)$} & \multicolumn{2}{|c|}{$(3)$} & \multicolumn{2}{|c|}{$(4)$} \\
\hline & Coeff. & Std. Err. & Coeff. & Std. Err. & Coeff. & Std. Err. & Coeff. & Std. Err. \\
\hline Provider Strictly Older & $0.663^{* *}$ & 0.125 & & & 1.222 & 0.349 & & \\
\hline Provider Same Gender & 0.995 & 0.106 & & & 0.870 & 0.170 & & \\
\hline Provider Same Ethnicity & $1.219^{* *}$ & 0.123 & & & 0.865 & 0.160 & & \\
\hline Provider Same Division & 0.976 & 0.108 & & & 1.284 & 0.260 & & \\
\hline Provider Tenure $\geq$ Median & 0.968 & 0.107 & & & 0.872 & 0.175 & & \\
\hline Provider Strictly More Educated & 0.967 & 0.140 & & & 1.058 & 0.280 & & \\
\hline Provider Strictly Lower Staff Level & $0.075^{* * *}$ & 0.075 & & & 0.473 & 0.341 & & \\
\hline Provider Younger or Same Age & & & 1.132 & 0.175 & & & 0.751 & 0.196 \\
\hline Provider Opposite Gender & & & 0.983 & 0.112 & & & 1.112 & 0.236 \\
\hline Provider Different Ethnicity & & & $0.814^{*}$ & 0.103 & & & 1.098 & 0.250 \\
\hline Provider Different Division & & & 1.001 & 0.122 & & & 0.741 & 0.176 \\
\hline Provider Tenure $<$ Median & & & 0.995 & 0.111 & & & 1.108 & 0.227 \\
\hline Provider same or lower education & & & 0.861 & 0.113 & & & 0.866 & 0.216 \\
\hline Provider Higher or Same Staff Level & & & 1.175 & 0.220 & & & 1.327 & 0.446 \\
\hline Log Likelihood & -4678 & & -4689 & & -2218 & & -2218 & \\
\hline Observations & 11,363 & & 11,363 & & 11,363 & & 11,363 & \\
\hline
\end{tabular}

Notes: Coefficient is the exp(coefficient). Omitted category is not referred, day shift, full time, not on leave, mid-level staff in the largest division. Controls include company divisions, tenure, starting salary, shift, leave status, full-time/part-time status, staff level, and a post-recession dummy. 


\section{Figure 1: Predicted salary trajectory with and without referral}

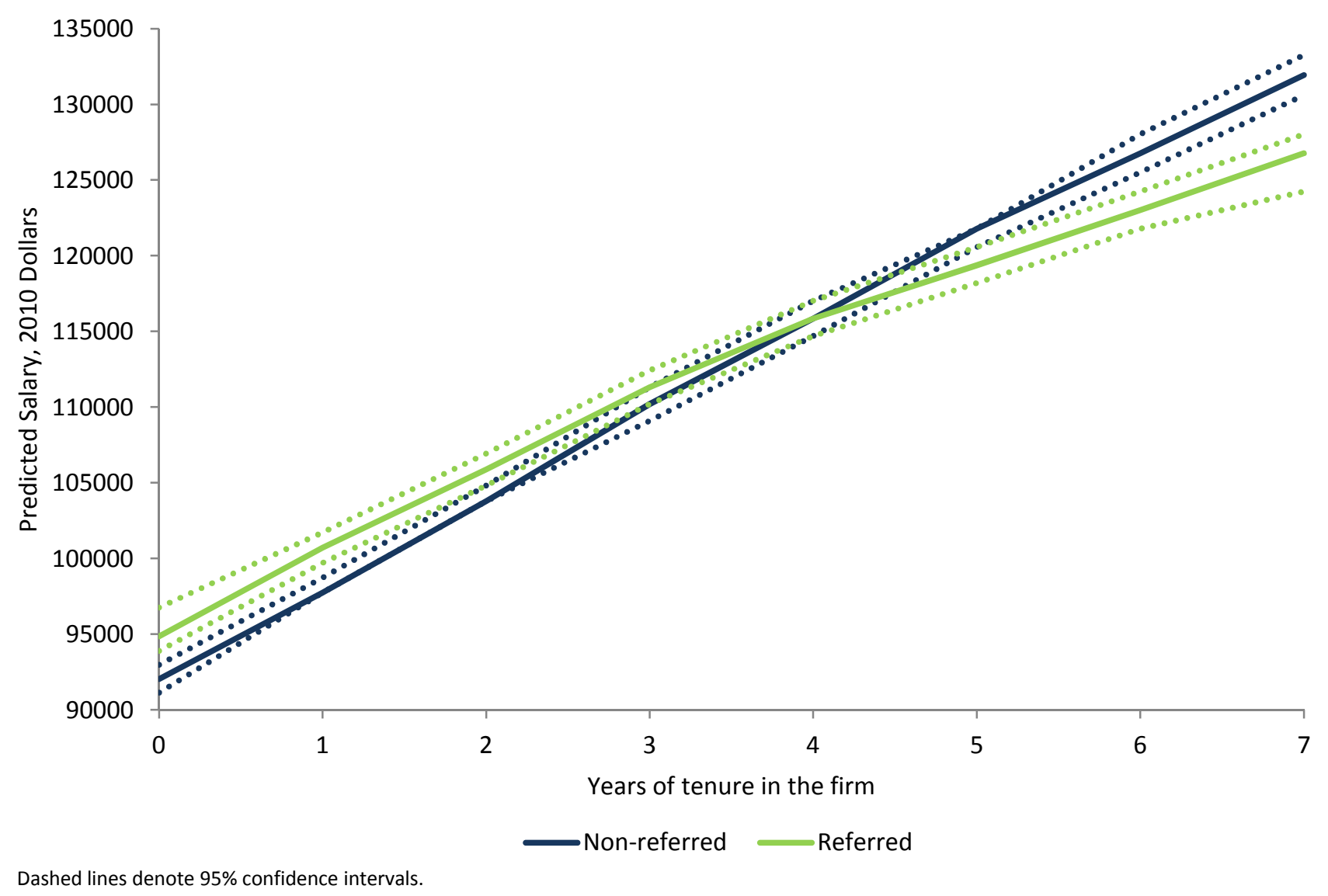




\section{Figure 2: Standard Deviation of Salary, Conditional on Table 6 Regressors}

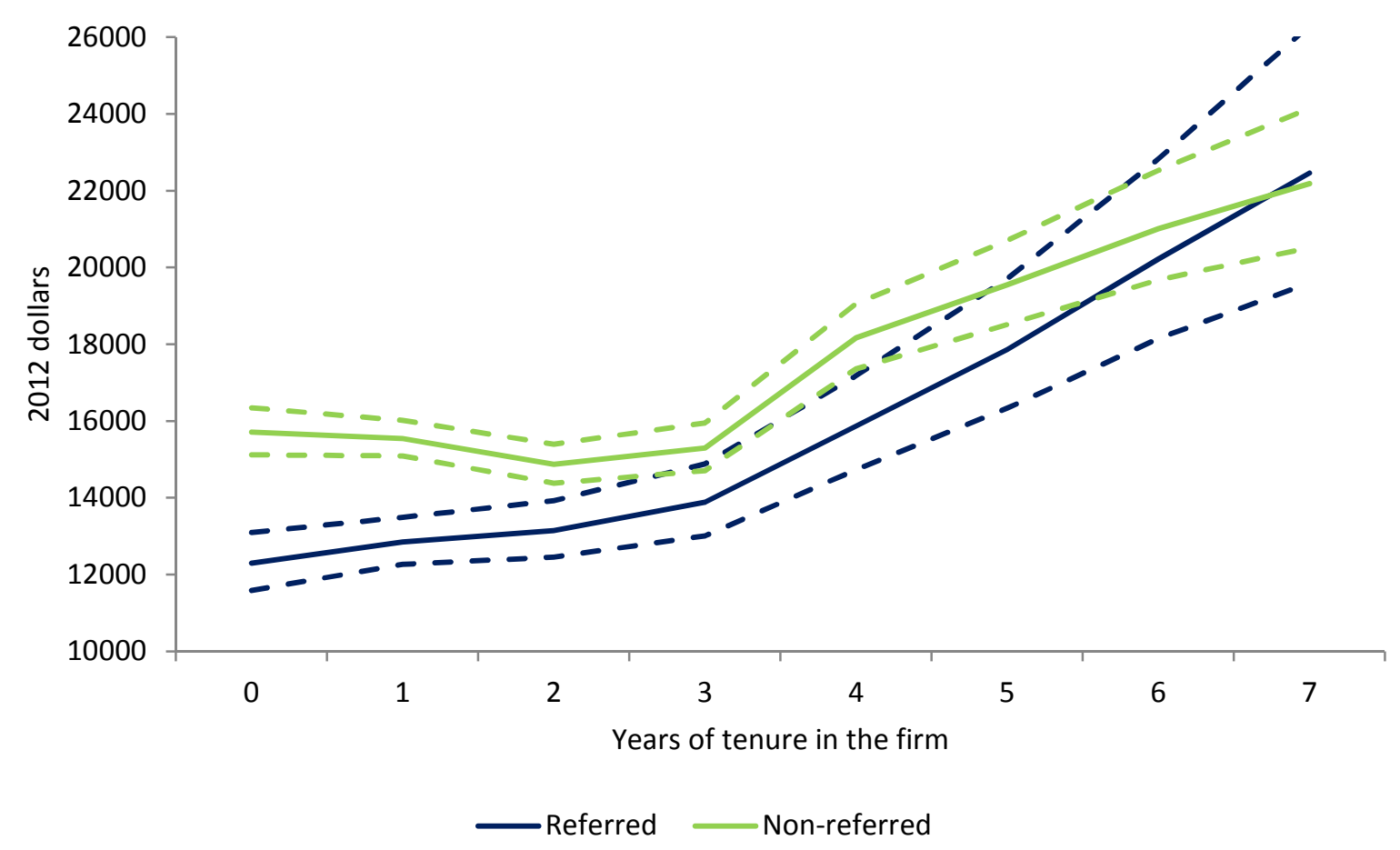

Dashed lines denote 95 percent confidence interval. 
Figure 3: Predicted Salary Trajectory by Provider-Receiver Affinity

a. Age

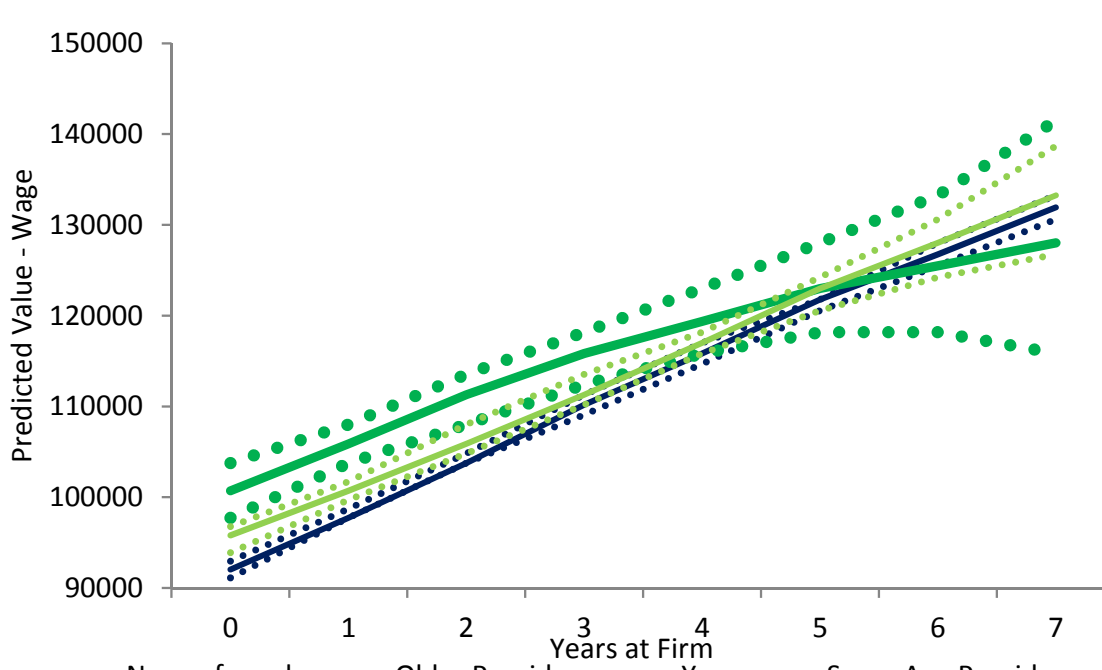

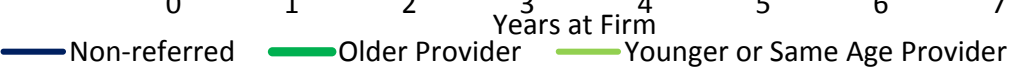

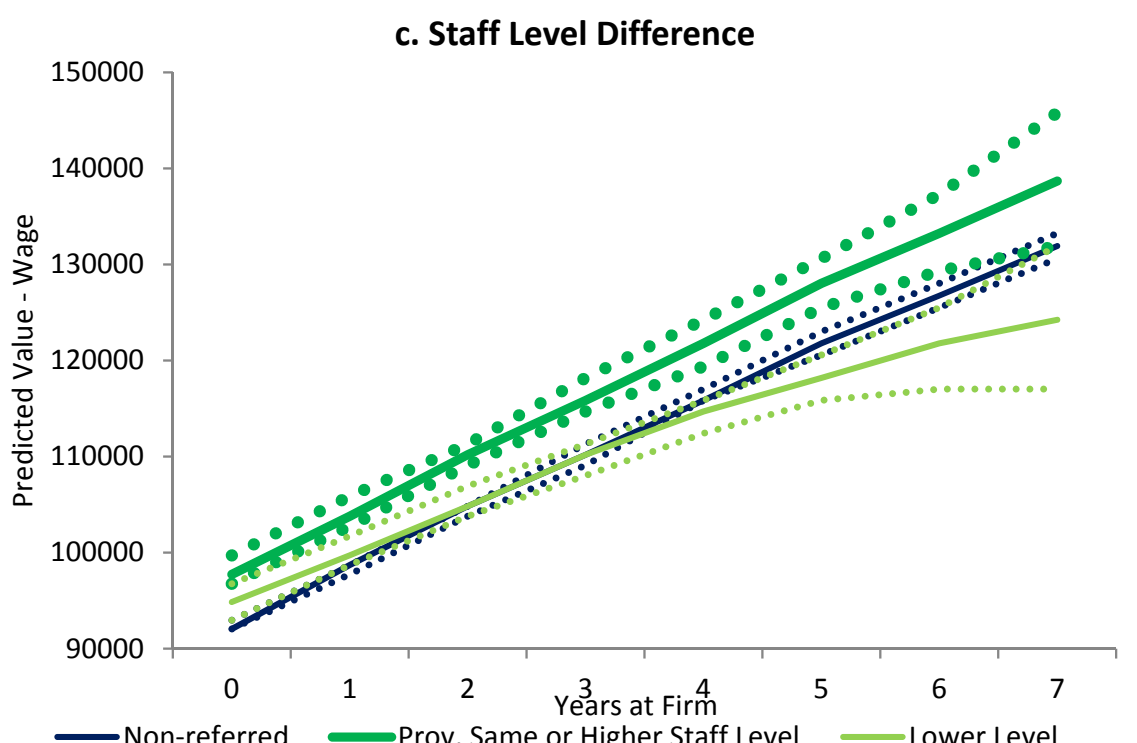

b. Tenure

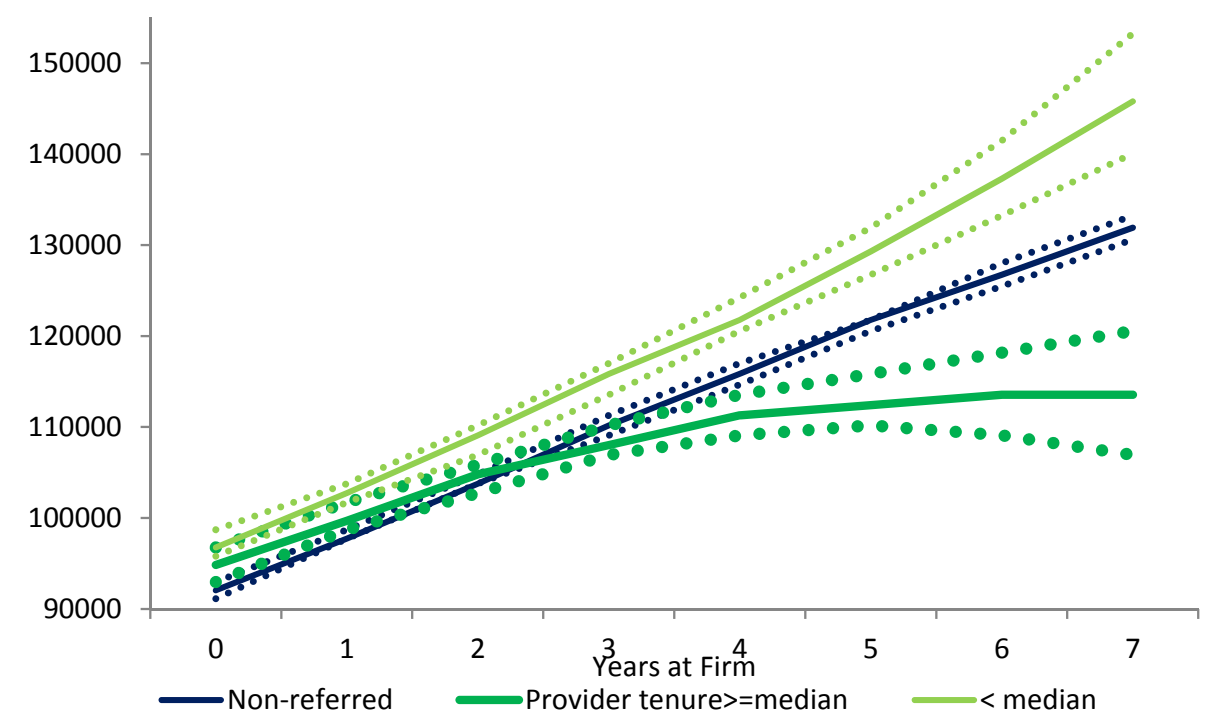

d. Division

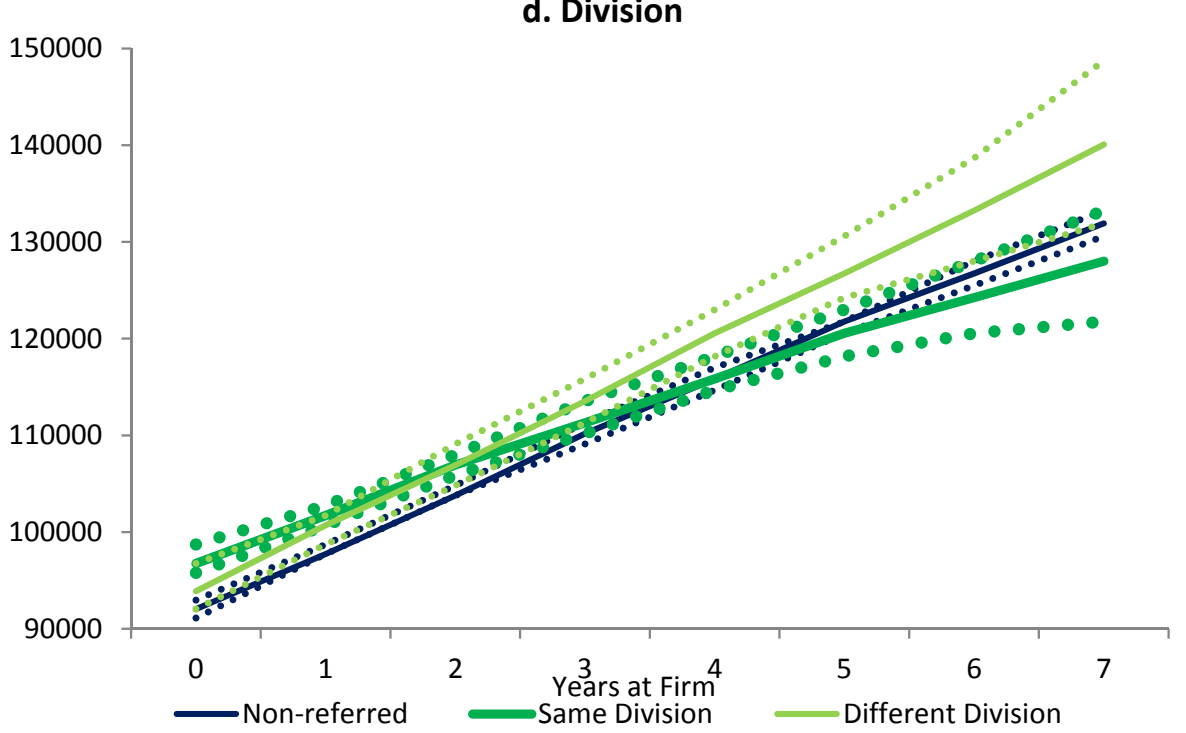

Dashed lines denote $95 \%$ confidence intervals. 
Figure A1: Referral salary premium by tenure, based on Table 6 column (2) estimates

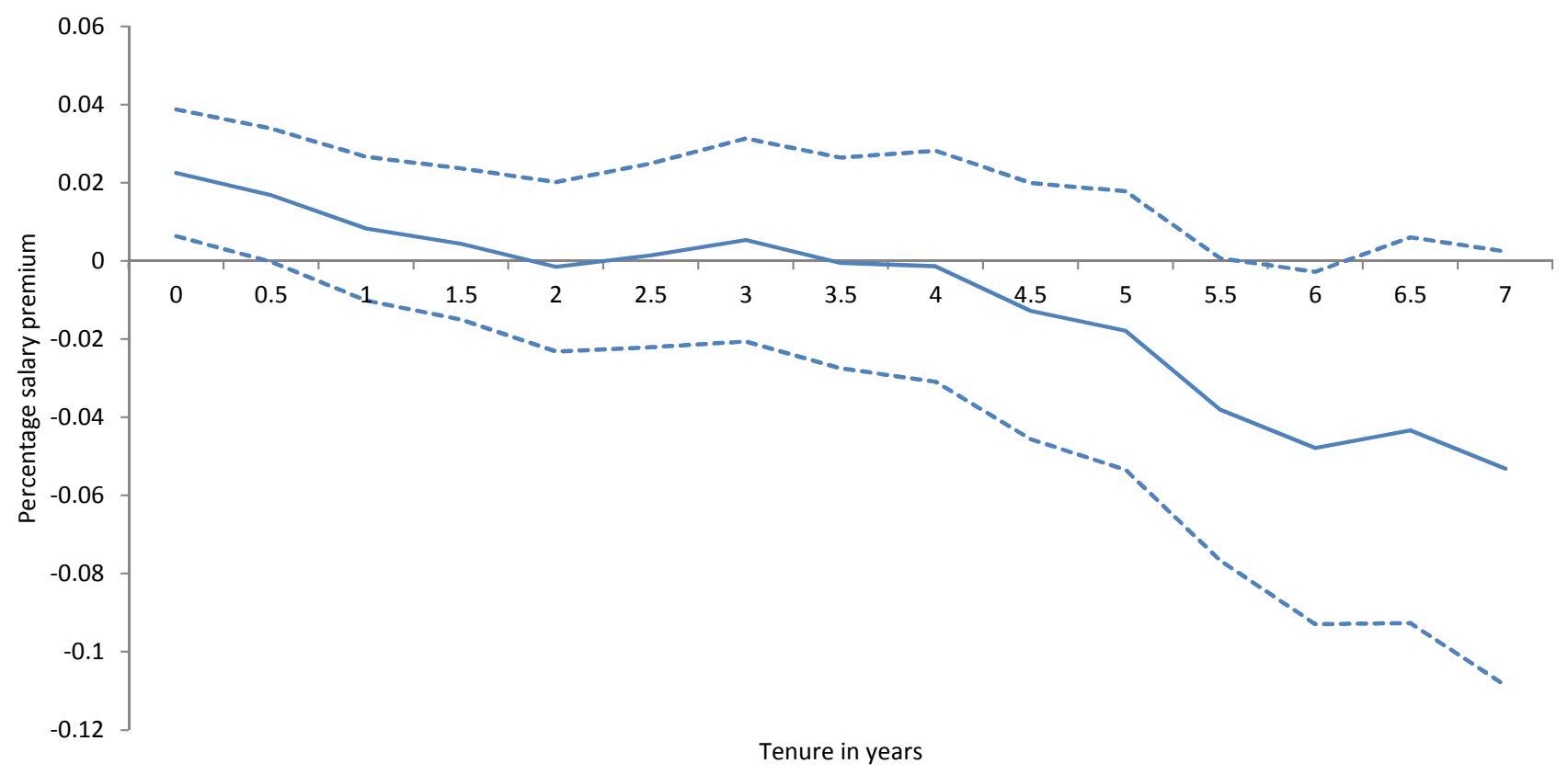

Dashed lines denotes 95 percent confidence interval. 
Figure A2: Predicted salary trajectory with and without referral - Tenure $\geq 5$ Years

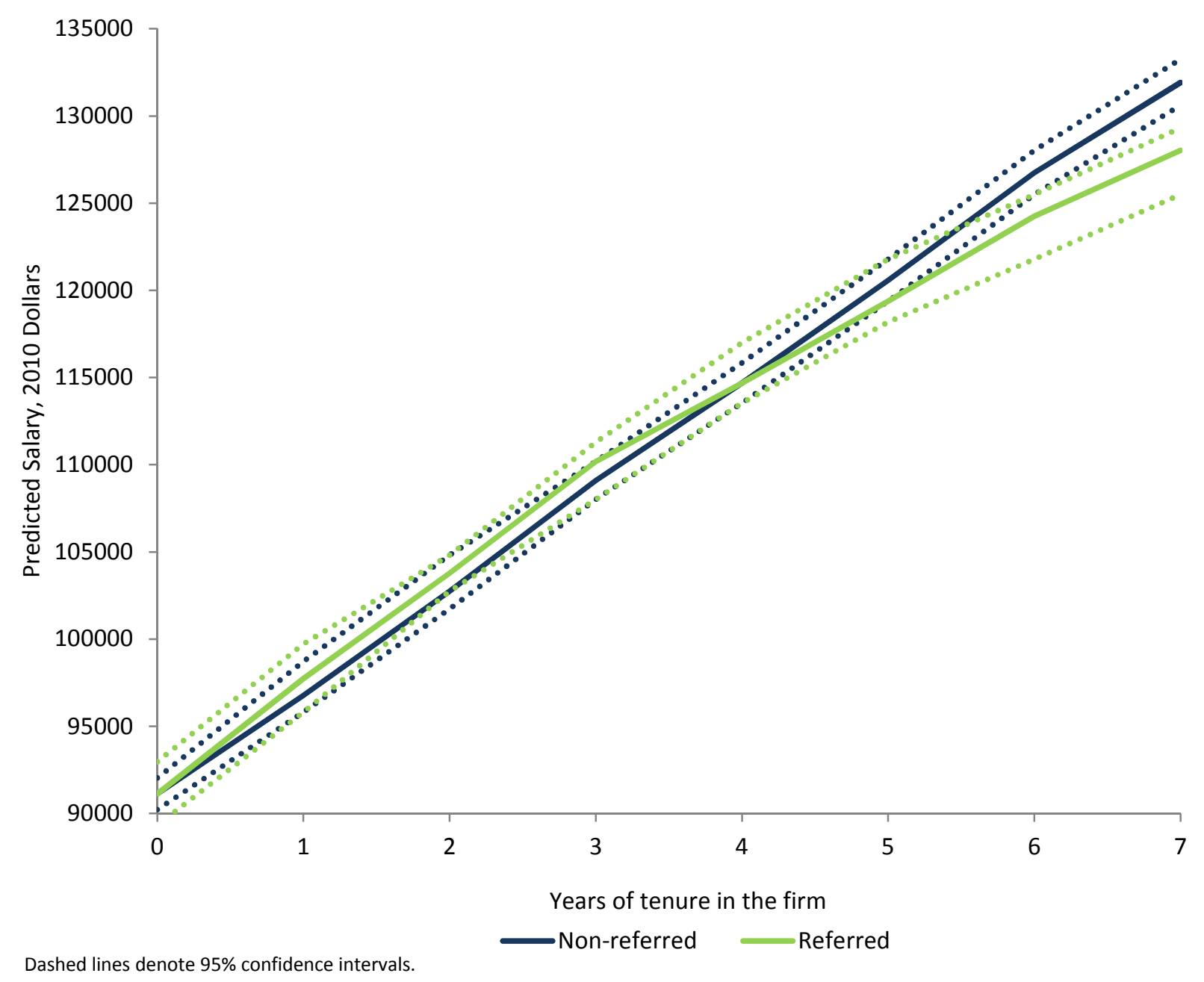

